\title{
Reuters Institute Digital News Report 2014: ESPAÑA
}

Samuel Negredo

Ramón Salaverría

Pamplona, 12 de junio de 2014

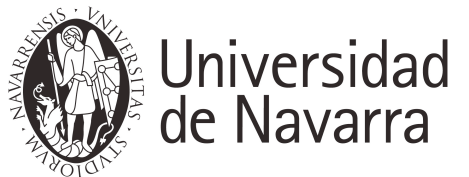




\section{ÍNDICE}

3. INTRODUCCIÓN

Un gran estudio global sobre el público de las noticias en internet y que indaga en las audiencias españolas

5. USO DE FUENTES TRADICIONALES Y DIGITALES PARA SEGUIR LA ACTUALIDAD Los menores de 35 años se informan en redes sociales y televisión casi por igual

7. PORTADAS VS PLATAFORMAS SOCIALES PARA DESCUBRIR INFORMACIONES LAS REDES COMPITEN CON WEBS Y 'APPS' DE MEDIOS COMO FORMA DE ACCESO A NOTICIAS

12. USO GENERAL DE DISPOSITIVOS Y ESPECÍFICO PARA CONSUMO DE NOTICIAS Tres de cada diez personas se informan en móvil o tableta más que en ordenador

15. COMPRA DE CONTENIDOS Y ABONO POR ACCESO A INFORMACIÓN DIGITAL EL 8,5\% PAGA POR NOTICIAS 'ONLINE'. ENTRE LOS DEMÁS, UN 21\% VE PROBABLE HACERLO

26. LA CABECERA, EL PERIODISTA Y LA CONFIANZA EN LA INFORMACIÓN LOS USUARIOS PREFIEREN LOS MEDIOS PLURALES, NEUTRALES E IMPARCIALES

29. MEDIOS TRADICIONALES Y DIGITALES PREFERIDOS POR LOS USUARIOS Las marcas televisivas ganan 'offline', pero los diarios dominan en internet 


\section{INTRODUCCIÓN}

Todos los datos incluidos en este informe corresponden a una encuesta realizada por YouGov para el Reuters Institute for the Study of Journalism de la Universidad de Oxford, en colaboración con otras organizaciones como la Universidad de Navarra.

El trabajo de campo se desarrolló íntegramente

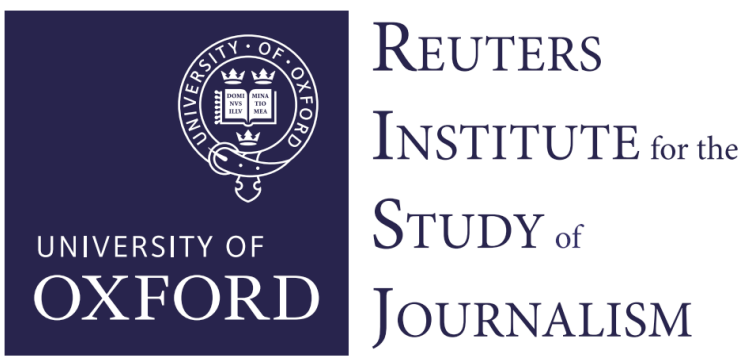
a través de formularios en internet, a finales de enero y principios de febrero de 2014, en diez países: Estados Unidos, Reino Unido, Alemania, Francia, Italia, España, Dinamarca, Finlandia, Japón y el Brasil urbano. En total, se procesaron las respuestas de 18.859 usuarios de internet, de los que 2.017 corresponden a España.

La muestra está estratificada y compensada por edad, género, región, lectura de periódicos y nivel formativo y de ingresos, para lograr la máxima representatividad posible, siempre dentro del universo de usuarios de internet que habían consumido noticias en algún momento del último mes. Este es el mayor estudio internacional sobre los usuarios de noticias digitales.

El análisis presentado en este informe se centra en España. Es un trabajo de investigadores del Center for Internet Studies and Digital Life de la Universidad de Navarra, que desde esta tercera edición anual es socio académico del Reuters Institute para la elaboración del Digital News Report, junto con el Instituto Hans Bredow de Hamburgo (Alemania), la Escuela de Periodismo de Sciences Po (Francia) y la Universidad de Roskilde (Dinamarca).

Los patrocinadores del Digital News Report 2014 son Google, BBC Global News, Ofcom, Newsworks, Edelman, France Télévisions y la Fundación para la Investigación en la Industria de los Medios (Finlandia). En su condición de socio académico, el Center for Internet Studies and Digital Life de la Universidad de Navarra supervisó el cuestionario para los usuarios de España y promovió preguntas específicas, de acuerdo con sus líneas de investigación.

El sitio digitalnewsreport.org ofrece acceso a la versión principal del informe en inglés elaborada por el Reuters Institute, tanto en formato PDF descargable como en versión web, con ensayos, análisis de todos los países, multitud de tablas y gráficos comparativos, y datos abiertos y reutilizables, todo ello publicado bajo licencias que facilitan su difusión.

Hay que tener en cuenta que la base sobre la que se extraen los porcentajes en todos los países es la de usuarios de internet que habían consumido noticias en el último mes. Dependiendo de la generalización del acceso a la red y de la existencia de grupos de usuarios de internet que se mantienen ajenos a la información de actualidad, los resultados son menos o más generalizables al conjunto de adultos del país.

Se considera una penetración de internet en España del 67\%, sólo por delante de Italia (58\%) entre los países europeos estudiados; Francia, Alemania, Reino Unido, Finlandia y Dinamarca están por encima, entre el $80 \%$ y el 90\%. Japón también llega al 80\% de acceso a internet; Estados Unidos se queda en el 78\%, y la población urbana de Brasil, en el 46\%.

Entre los usuarios de internet, un 3\% de los españoles y de los alemanes dijo no haber consultado noticias en línea en el último mes; un grupo aún más pequeño en Finlandia (1\%), 
y en Italia, Dinamarca, Japón y las ciudades de Brasil (2\%). Sin embargo, los usuarios de internet que dicen no haber visto ni leído noticias en el último mes representaron un $5 \%$ de los encuestados en Francia y un 8\% tanto en Reino Unido como en Estados Unidos.

La encuesta permite dibujar algunos perfiles. Por ejemplo, entre los usuarios más jóvenes. Sólo un 33\% de los que se informan en internet y que tienen entre 18 y 24 años visita directamente los sitios web y las aplicaciones de los medios, mientras que un $36 \%$ las encuentra a través de Twitter. En esta franja de edad, las redes sociales (62\%) están a punto de desbancar a la televisión (65\%) como principal fuente informativa; de hecho, ya superan a los sitios web y a las aplicaciones de los medios en seis puntos porcentuales.

Un 45\% de estos usuarios jóvenes se informa principalmente a través del móvil (y un $8 \%$ adicional en la tableta), frente al $44 \%$ que lo hace sobre todo a través del ordenador. Además, los usuarios con edad entre 18 y 24 años son los que ven más probable pagar en el futuro por noticias en internet (28\%), junto con la franja de edad inmediatamente superior.

Como puede comprobar en las próximas páginas, los públicos de la información en internet son cada vez más amplios y heterogéneos, por la mayor variedad en dispositivos y modalidades de acceso, formatos de consumo y posibilidades de participación. Disponer de una encuesta amplia, incluso cuando nos centramos en el mercado español, nos permite distinguir los grupos demográficos y de uso que están más o menos avanzados en la adopción de determinadas innovaciones, propuestas y marcas informativas.

En términos generales, entre los diez estudiados, los usuarios españoles que consultan noticias en internet son los únicos que confían más en la firma de periodistas concretos, que en los medios de comunicación como organizaciones con una marca y una línea editorial.

España, que centra la atención de este informe, también destaca entre el resto de mercados estudiados por el uso de WhatsApp para compartir y comentar noticias, que resulta excepcional entre los países de su entorno, y por las altas tasas de participación en torno a los contenidos informativos, por encima de la media del conjunto de países en todas las modalidades... excepto en la publicación de comentarios en sitios web de noticias.

\section{CENTER FOR INTERNET STUDIES AND DIGITAL LIFE. FACULTAD DE COMUNICACIÓN. UNIVERSIDAD DE NAVARRA}

El Center for Internet Studies and Digital Life, asociado a la Facultad de Comunicación de la Universidad de Navarra, se fundó en septiembre de 2013 con la misión de fomentar la investigación en las formas y el impacto de la actividad digital en el complejo y cambiante campo de la comunicación. La creación del Center es otro hito en la trayectoria académica de la Facultad, en la que los medios digitales se han abordado en la docencia y en la investigación desde que internet emergiera como medio global a mediados de los años 1990.

Más de 30 profesores trabajan actualmente en el Center for Internet Studies and Digital Life, que comprende tres áreas: personas, contenidos y empresas. Cada área comprende varios campos de investigación, como el uso de las redes sociales, el periodismo digital, la publicidad interactiva, los nuevos modelos de negocio para las empresas de comunicación, y el impacto de internet en campañas electorales, entre otros. Puede consultar más información sobre el equipo, las líneas de investigación y las publicaciones del Center for Internet Studies and Digital Life en el sitio web unav.edu/digitalstudies y en la cuenta de Twitter @digitalunav. 


\section{LOS MENORES DE 35 AÑOS SE INFORMAN EN REDES SOCIALES Y TELEVISIÓN CASI POR IGUAL}

\section{- Los informativos de las grandes cadenas siguen predominando en España: 3 de cada 4 internautas los vieron en la última semana}
- Leen noticias en redes sociales casi tantos usuarios (46\%) como los que lo hacen en diarios impresos (47\%) y periódicos 'online' $(49 \%)$

\section{- Los sitios y las aplicaciones de marcas periodísticas sólo presentes en internet son casi tan seguidos como los de radios y televisiones}

Los medios tradicionales llegan a un $\mathbf{9 2 \%}$ de los usuarios de internet que consumen noticias. Esto son algunos resultados agregados, que complementan el desglose que se presenta en el gráfico inferior: un $\mathbf{5 1 \%}$ de internautas dice leer también medios periodísticos impresos (diarios y revistas), y el conjunto de noticias en televisión (informativos y canales 24 horas) suma una audiencia del $85 \%$ a lo largo de la semana.

El conjunto de fuentes digitales de noticias alcanza al $\mathbf{8 1 \%}$ de los usuarios, incluyendo redes sociales, blogs, publicaciones informativas sólo digitales, y versiones en internet de marcas y cabeceras 'offline'. La suma de medios sociales y blogs alcanza a un $49 \%$ de los consumidores de noticias conectados a la red; la versión en internet de los medios tradicionales (periódicos, revistas, radios y televisiones) llega a un 62\% del público 'online'.

¿Cuáles de las siguientes fuentes de noticias ha utilizado en la última semana?

Posibilidad de respuesta múltiple (Base: 2.017 usuarios en España)

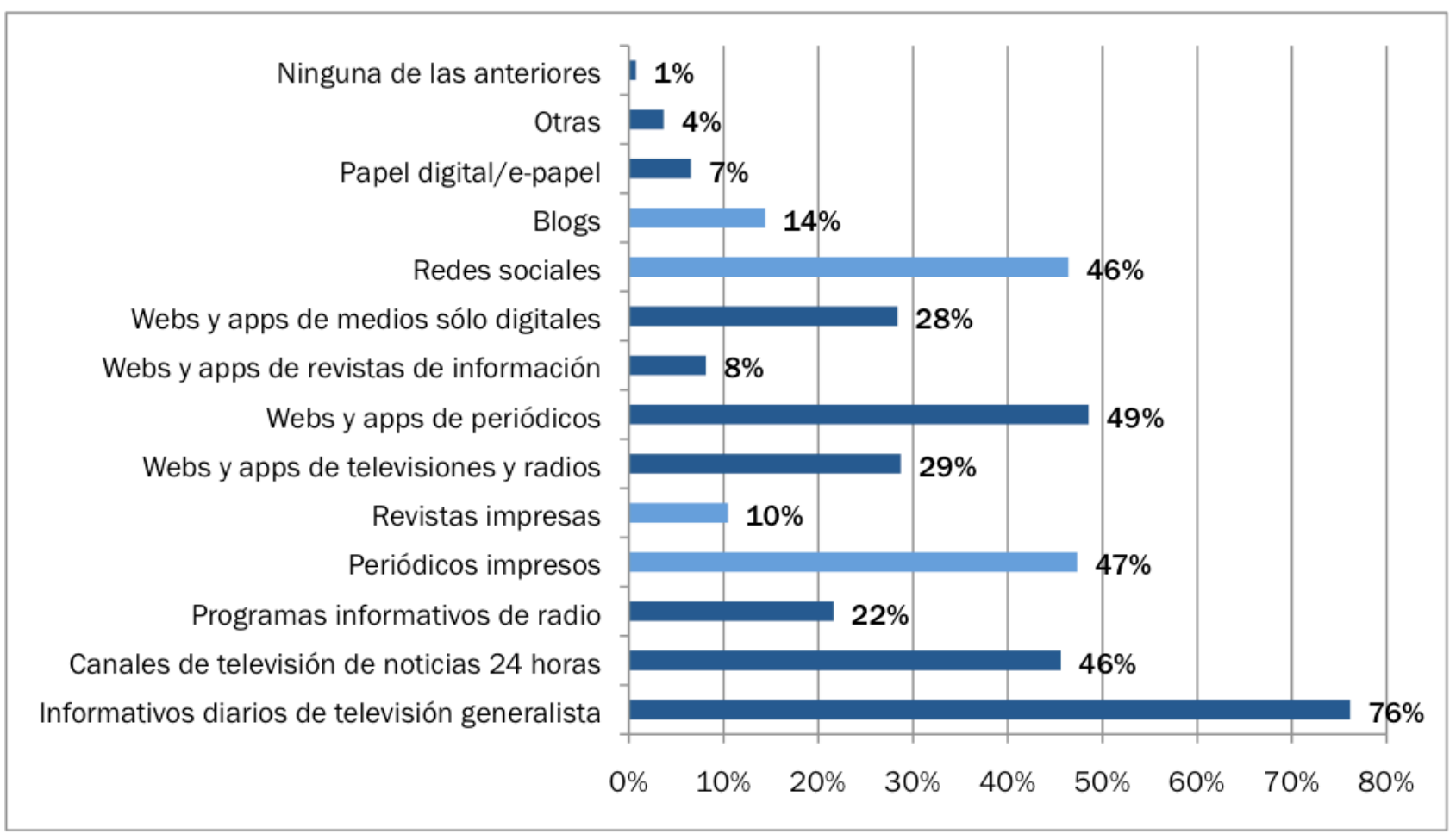


¿Cuáles de las siguientes fuentes de noticias ha utilizado en la última semana?

Posibilidad de respuesta múltiple. (Base: 2.017 usuarios en España)

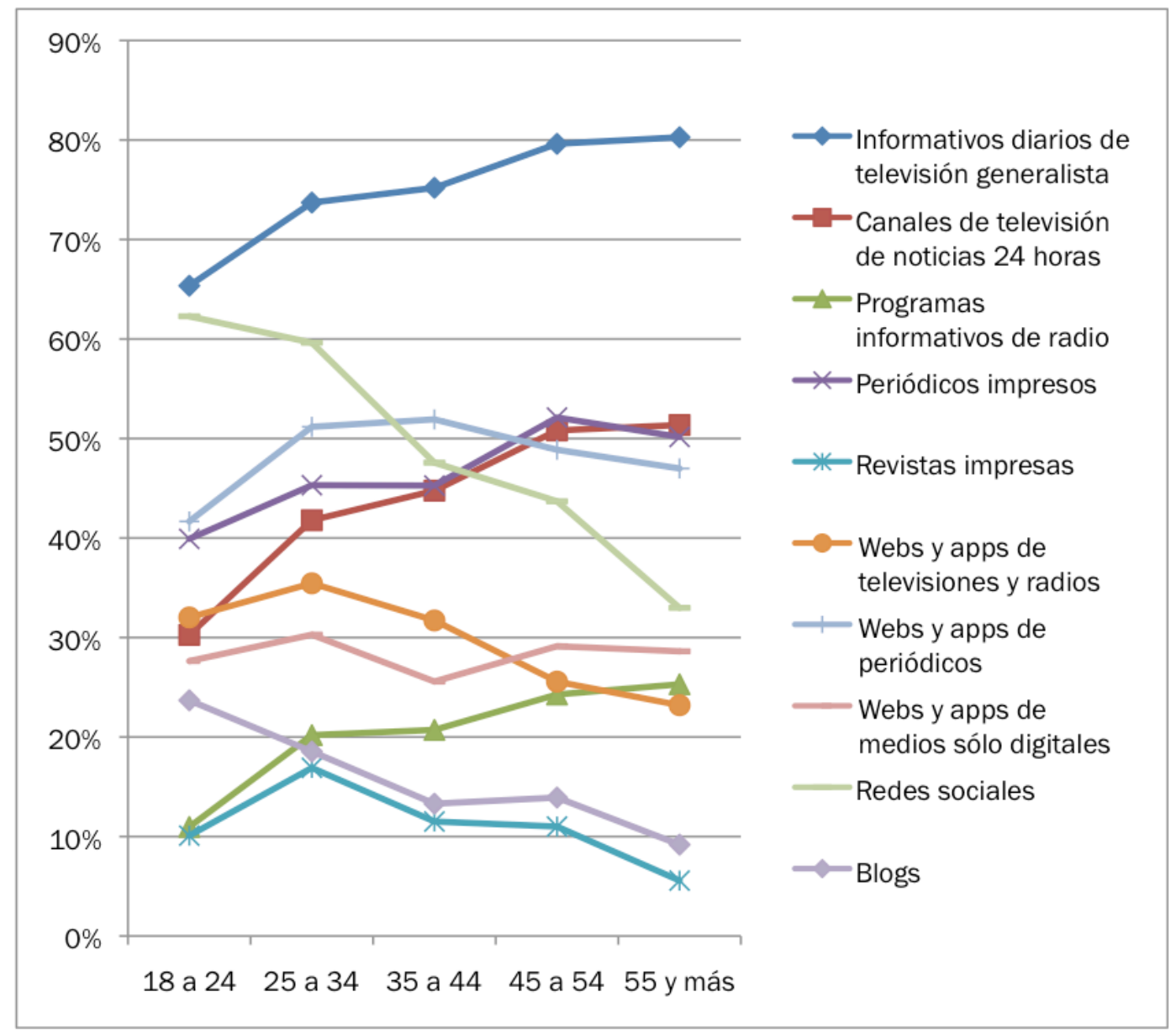

Las redes sociales son el segundo medio de referencia de los usuarios de internet menores de 35 años en España, sólo por detrás de la televisión convencional. Plataformas como Twitter y Facebook ya superan a los diarios impresos como fuente informativa incluso entre los usuarios de la franja de 35 a 44 años.

El seguimiento más homogéneo corresponde a las marcas periodísticas presentes sólo en internet, sin equivalente en los quioscos o en las ondas, con una audiencia estable entre el $26 \%$ y el $30 \%$ en todas las franjas de edad.

La lectura de sitios web y aplicaciones de periódicos es nueve puntos porcentuales inferior en la franja de 18 a 24 años (42\%) que en la de 25 a 34 años (51\%). La radio duplica su seguimiento como medio informativo a partir de los 25 años (20\% o más), frente al escaso $11 \%$ de los adultos menores de 25.

El seguimiento de noticias en televisión generalista entre adultos menores de 25 desciende al $65 \%$, un porcentaje similar al de jóvenes del mismo grupo de edad que se enteran de las noticias a través de las redes sociales (62\%). A partir de los 45 años se sitúa en torno al $80 \%$.

El conjunto de ofertas televisivas de información continua como el Canal 24 Horas de Televisión Española, Euronews o el canal 3/24 en Cataluña tienen un 51\% de penetración entre usuarios de 45 años y más y son el segundo tipo de fuente más consultado por los mayores de 55, mientras que entre los menores de 45 apenas son la quinta o la sexta opción. 


\title{
LAS REDES COMPITEN CON WEBS Y 'APPS' DE MEDIOS COMO FORMA DE ACCESO A NOTICIAS
}

\author{
- El 38\% de los internautas españoles se entera de la última hora en \\ redes sociales. Un $46 \%$ accede para ello a los medios informativos
}

\section{- Los usuarios más jóvenes entran más a Twitter y a Facebook que a sitios web y aplicaciones de medios para seguir la actualidad}

\section{- Los buscadores se emplean para introducir el nombre del sitio al que se desea acceder, más que para consultar asuntos específicos}

La forma más extendida de conocer noticias nuevas entre los usuarios españoles es acceder directamente al sitio web o la aplicación de un medio; el $46 \%$ de los encuestados se informa de esta manera. Esta modalidad se da en mayor medida entre hombres (50\%) que entre mujeres (43\%), y crece cuanto mayor es la edad de los usuarios, como se puede observar en el gráfico de la página siguiente: por edades, se va incrementando desde el 33\% hasta el 53\%.

Las redes sociales en conjunto son empleadas para informarse por un $\mathbf{3 8 \%}$ de los usuarios: un 15\% del total encuentra noticias a través de Twitter, y el 30\% conoce informaciones nuevas a través otras redes sociales, como Facebook, Google+, Linkedin o cualquiera distinta de Twitter. El dato agregado convierte a las redes sociales en el segundo tipo de fuente informativa para el usuario español medio, si bien ya es el primero entre los de 18 a 24 años.

El perfil de seguimiento de Twitter es muy distinto según edades, y las otras redes difieren más según el género del usuario o la usuaria. Twitter (36\%) supera a la suma de todas las demás redes (33\%) entre los usuarios más jóvenes, pero su uso como fuente de noticias decrece a menos de la mitad (15\%) entre los usuarios de 35 a 44 años, y a una cuarta parte (9\%) a partir de los 45. Entretanto, el resto de redes sociales se mantiene en valores que oscilan entre el $33 \%$ y el $28 \%$ en todos los grupos de edad. Hombres y mujeres componen por igual ese $15 \%$ de usuarios que se informan a través de Twitter, pero en el uso del conjunto de resto de redes para recibir noticias hay una diferencia de nueve puntos porcentuales a favor de las usuarias.

Los buscadores son la tercera modalidad de acceso, con un 35\% de personas que emplean internet para informarse y que descubren noticias a través de ellos. Eso sí: se emplean más para buscar el nombre de un sitio web concreto (23\%), es decir, como mero acceso a sitios web decididos de antemano, que para buscar palabras clave de historias o temas específicos (20\%). Sólo es al revés, y por apenas dos puntos de diferencia, en el grupo entre 45 y 54 años.

Las alertas y los boletines por correo electrónico son un recurso empleado por el $12 \%$ de los usuarios que se informan en internet, con una popularidad del 17\% entre hombres de 45 a 54 años. Las alertas en el teléfono móvil, por mensaje de texto o lanzadas por una aplicación, son una fuente informativa para apenas el $5 \%$ de los usuarios españoles en la actualidad.

Algo más populares son las aplicaciones que agregan varias fuentes, como Flipboard, Zite o Pulse (total: 7\% de usuarios), pero sólo entre los menores de 45 años (11\%) 


\section{LOS ADULTOS MENORES DE 25 AÑOS RECURREN A TWITTER (36\%) Y A OTRAS REDES (33\%) TANTO COMO A LOS MEDIOS INFORMATIVOS (33\%) PARA DESCUBRIR NOTICIAS NUEVAS}

Piense en las noticias a las que ha accedido en línea (mediante un ordenador, un móvil u otros dispositivos) durante la última semana; ¿de qué formas ha descubierto noticias nuevas? Seleccione todas las que correspondan (Base: 2.016 usuarios en España)

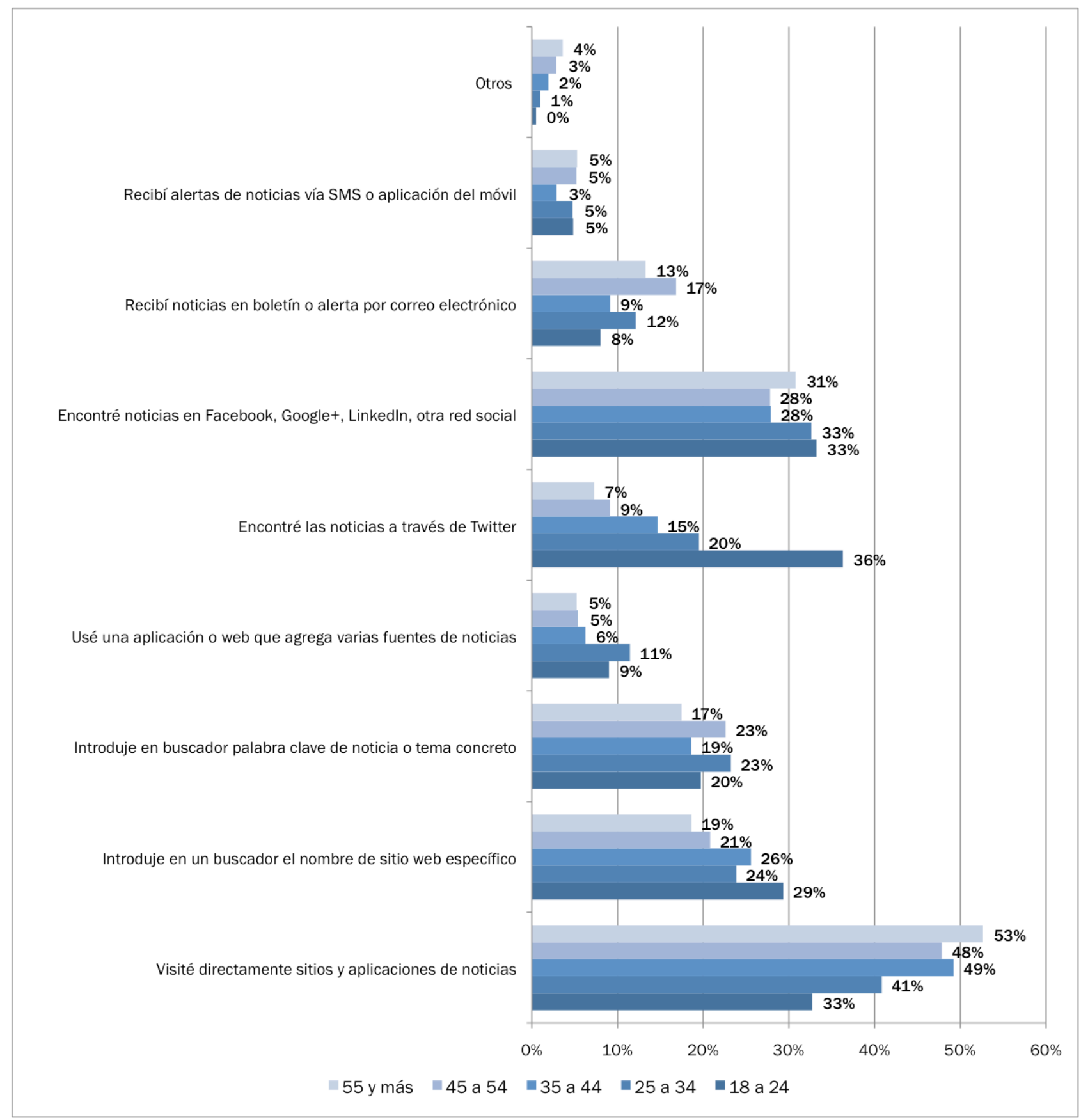

Si miramos al contexto global, España destaca por el 15\% de usuarios que descubren noticias en Twitter, que es más del doble que en el conjunto de países (7\%). Sólo se acerca Brasil urbano con un 10\%; en el resto, descubre noticias en Twitter un $8 \%$ (Reino Unido y Japón), un 7\% (Estados Unidos e Italia), el 5\% (Francia) o apenas un 2\% o 3\% (Alemania, por ejemplo). 
Sin embargo, la popularidad de plataformas alternativas a Twitter aúpa a Brasil (zonas urbanas) al primer puesto entre los mercados cuyos usuarios descubren noticias a través de otras redes sociales, con un $46 \%$ que han encontrado informaciones de esta forma en la última semana, frente al 38\% de España (en segunda posición) o al 34\% de Italia (tercer país).

Con un $28 \%$, Estados Unidos también supera ampliamente la media global del $23 \%$ de uso de redes sociales para informarse. Salvo Finlandia, que está en el 24\%, el resto de países europeos queda por debajo: 17\% en Reino Unido, 16\% en Dinamarca, 15\% en Alemania y 14\% en Francia. En Japón apenas es un 12\%.

\section{POCO MÁS DE UN TERCIO DE LOS USUARIOS MUNDIALES SE} INFORMA ACCEDIENDO DIRECTAMENTE AL SITIO WEB O A LA APLICACIÓN. EN FRANCIA Y ALEMANIA, APENAS 1 DE CADA 4

Recurren al acceso directo al sitio o a la aplicación de noticias, en la misma proporción que los españoles (46\%), los usuarios de Dinamarca y el Brasil urbano, y de forma muy similar (45\%) en Reino Unido. Sólo en Finlandia accede directamente a los sitios más de la mitad de los usuarios (57\%). Sin embargo, hay países como Japón, Francia o Alemania, en los que apenas se informa así uno de cada cuatro usuarios. La media global es del 37\%, siempre considerando la última semana.

A pesar de su escasa popularidad en países como Reino Unido (9\%), España, Italia y Alemania (12\% en los tres mercados), los boletines y las alertas por correo electrónico cuentan con un seguimiento global del 16\%, sobre todo debido a su éxito en Estados Unidos (27\%), Francia (24\%) y el Brasil urbano (22\%). Las alertas a móviles, tanto por SMS como a través de aplicaciones nativas, tienen tan poco impacto en España como a escala global; se entera de noticias a través de ellas apenas un $5 \%$ de usuarios en el conjunto de mercados.

¿Cuáles de los siguientes servicios ha usado por cualquier motivo durante la última semana? ¿Cuáles de los siguientes servicios ha usado para leer, ver, compartir o comentar las noticias durante la última semana?

Posibilidad de respuesta múltiple. Ordenados por uso para noticias (Base: 2.017 usuarios en España)

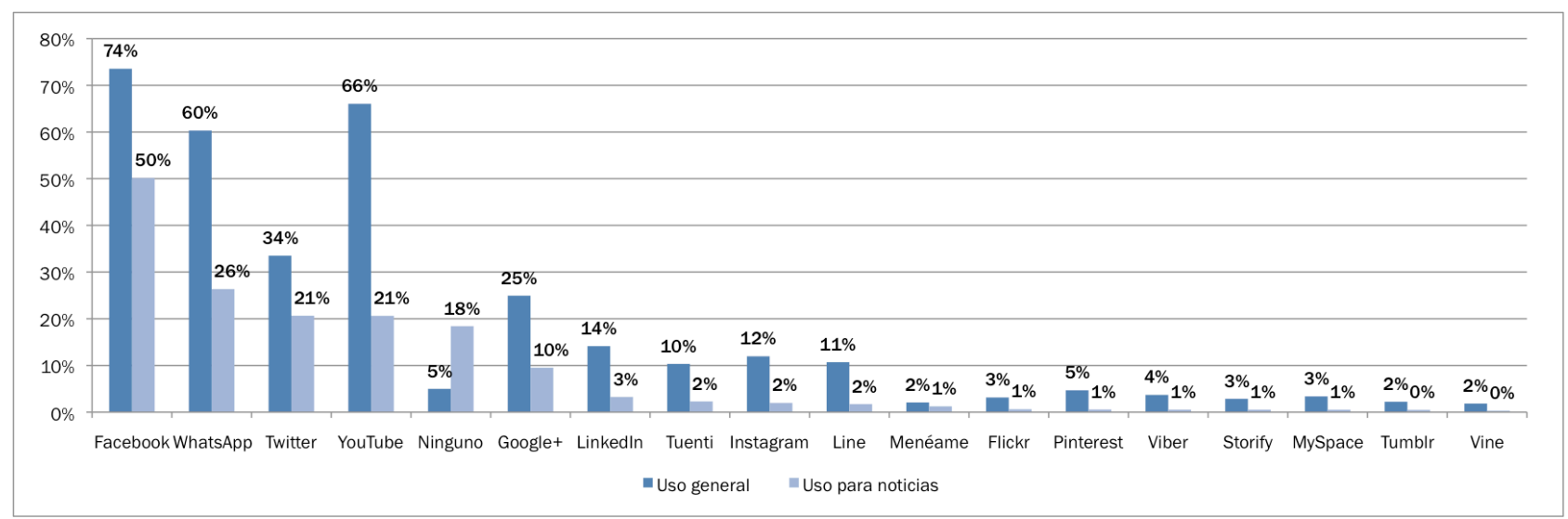

Las cuatro plataformas sociales más empleadas para seguir la actualidad informativa en España son Facebook, con uno de cada dos usuarios; WhatsApp, con uno de cada cuatro, y tanto Twitter como YouTube: en ambos casos, se informa a través de ellas uno de cada cinco usuarios, pese a la mayor popularidad en general de la plataforma de vídeos. 
En España recurre a Google+ para informarse uno de cada diez usuarios, lo que la convierte en quinta red social para acceder a la información de actualidad, según los encuestados.

Si agregamos los datos, un 57\% de usuarios españoles empleó Facebook o Twitter (al menos uno de los dos) con fines informativos en la semana previa a la encuesta; el porcentaje sube al $64 \%$ si se considera la terna de Facebook, Twitter o YouTube.

A escala internacional, la plataforma más popular para leer, ver, compartir o comentar las noticias es Facebook, con un 35\% de media. En segundo lugar está YouTube, con el 15\%. El tercer medio social es Twitter, empleado por el 9\%; el cuarto sitio social para noticias es Google+ (7\%), y en quinto lugar queda la aplicación WhatsApp, con el 6\%. Por tanto, coinciden los cinco servicios más populares en España y en el conjunto de países, aunque no en el mismo orden. Linkedin es la siguiente opción a escala global (y también en España) con un 3\% de usos relacionados con las noticias (mismo dato que en el país), y el resto no pasa del 1\%.

\section{EL $60 \%$ DE LOS INTERNAUTAS ESPAÑOLES EMPLEA WHATSAPP. ENTRE TODOS SUS USUARIOS, EL 43\% VIO O COMPARTIÓ NOTICIAS EN LA APLICACIÓN DE CHAT EN LA ÚLTIMA SEMANA}

Dos mercados superan el $\mathbf{5 0 \%}$ registrado en España para el uso de Facebook como fuente de información y conversación en torno a la actualidad: los usuarios urbanos de Brasil (67\%) y los italianos (57\%). Estados Unidos (37\%) también está por encima de la media, mientras que los demás países europeos se quedan entre el 22\% y el 32\%, y Japón, apenas en el 12\%; sólo en este último país se emplea más YouTube (15\%) que Facebook en relación con las noticias.

WhatsApp está mucho más localizado en mercados concretos: España, con el 26\%, más que cuadruplica el resultado total del $6 \%$ en el conjunto de países, lo que lo convierte en el territorio en que más se emplea este servicio de mensajería instantánea como plataforma para ver, compartir y comentar noticias. En segundo lugar quedan las zonas urbanas de Brasil, con el 15\%, y en el tercer puesto, Italia, con el $13 \%$.

La proporción del uso de WhatsApp para compartir y comentar noticias sobre el uso general de la plataforma es muy parecida en los tres países: un poco menos de la mitad. Por contraste, pese a que en Alemania y Reino Unido utiliza WhatsApp un 30\% y un 12\% de los encuestados, respectivamente, sólo uno de cada cinco de esos usuarios dice haberlo empleado para leer, ver, comentar o compartir noticias: $6 \%$ del total de usuarios en Alemania, y $2 \%$ en Reino Unido.

La media global de uso informativo de Twitter en los países estudiados es del 9\%; España, con el $21 \%$, más que duplica este dato; le siguen, también por encima de la media pero ya a mucha distancia, el Brasil urbano (13\%), Reino Unido (12\%), Japón (11\%) e Italia (10\%). Por debajo de la media, Estados Unidos (8\%) y Francia (7\%), entre otros.

En uso general, YouTube queda ligeramente por detrás de Facebook en todos los países excepto Japón; la media es de $52 \%$ de uso general de YouTube frente al $60 \%$ de Facebook. Sin embargo, la media global de uso de YouTube para leer, ver, compartir o comentar noticias es de apenas el 15\%. Se sitúan por encima de la media, en este orden, el Brasil urbano (33\%), Italia (23\%), España (21\%), Estados Unidos (17\%) y Francia (16\%). 


\section{NOTICIAS EN REDES: FACEBOOK Y WHATSAPP, EQUILIBRIO POR EDADES. TWITTER, HERRAMIENTA INFORMATIVA PARA JÓVENES. GOOGLE+, MÁS USADO ENTRE MAYORES DE 45}

Por edades, el uso informativo de Facebook está bastante equilibrado en España (apenas oscila entre el $58 \%$ y el $46 \%$ ), pero en el conjunto de los países decrece algo más conforme avanza la edad: del $43 \%$ al $28 \%$.

Algo similar sucede con WhatsApp como plataforma para noticias: el equilibrio entre franjas de edad (en España apenas pasa del 32\% entre los más jóvenes al 23\% entre los más mayores) es mucho mayor aquí que en el resultado de todos los países, en el que del $9 \%$ de los menores de 35 años pasa al 4\% o $5 \%$ de los mayores de 45 años.

Sin embargo, sí se observan patrones de edad similares en la utilización de Twitter para noticias entre los usuarios de España y entre los encuestados en el conjunto de países: el 44\% español y el 19\% global en la franja de 18 a 24 años quedan reducidos a menos de dos terceras partes (25\% y 11\%, respectivamente) en el siguiente grupo de edad, de 25 a 34 años, y aproximadamente a una tercera parte (respecto de los más jóvenes) en el grupo de mayor edad, a partir de 55 años: un 14\% en España y un 6\% en los resultados globales.

También se repiten los patrones de edad en España y en el mundo para YouTube: la adopción de la plataforma de vídeos para uso informativo es mayor en el grupo más joven (26\% en España y 19\% global), y en el resto oscila ligeramente (18\%-22\% en España, 14\%-15\% global).

Por último, hay que destacar que la 'pirámide de población' se invierte en Google+: en España, su adopción como plataforma de noticias es de apenas un $7 \%$ en todos los grupos menores de 45 años, y sube a un 12\% a partir de esa edad. En el conjunto de países sucede lo mismo: $5 \%$ en las tres franjas de usuarios más jóvenes, y $9 \%$ en las dos franjas de mayores. 


\section{TRES DE CADA DIEZ PERSONAS SE INFORMAN EN MÓVIL O TABLETA MÁS QUE EN ORDENADOR}

\section{- En España, por cada iPhone hay cinco teléfonos inteligentes de otras marcas, y por cada iPad, dos tabletas no fabricadas por Apple}

\section{- El $75 \%$ de los usuarios de iPhone y el $62 \%$ de los de iPad los usan para informarse. Otras marcas: $58 \%$ en móviles y $48 \%$ en tabletas}

\section{- Entre adultos menores de 25 el teléfono (45\%) supera por la mínima al ordenador (44\%) como principal forma de conocer la actualidad}

Un 78\% de los usuarios de internet en España emplea un ordenador portátil o de sobremesa; se encuentra en la media global. Entre los diez estudiados, este es el país con mayor cuota de mercado para móviles y tabletas de marca distinta de Apple: el promedio total es del 49\%, mientras que en España alcanzan el 68\%. Un 62\% de los usuarios españoles de internet emplea teléfonos móviles inteligentes de otras marcas; es la mayor proporción en los diez países del estudio, frente al $12 \%$ de terminales iPhone. Además, España está casi a la par con el Brasil urbano en la utilización de tabletas no fabricadas por Apple, con $27 \%$ de usuarios que las emplean para cualquier fin; aquí sólo maneja un iPad la mitad de ese público, un 13\%.

Hablando siempre de uso general (todavía no específico para noticias), el mercado que estudiamos también es el que presenta mayor cuota para los lectores de libros electrónicos (18\%), seguido del Reino Unido (17\%) y Alemania (16\%). Igualmente, es el país europeo en el que más usuarios, en proporción, afirman que utilizan un televisor inteligente o conectado (23\% frente al $21 \%$ de Francia, el $20 \%$ de Alemania o el $17 \%$ del Reino Unido).

¿Cuáles de los siguientes dispositivos utiliza alguna vez (no importa el motivo)? ¿Cuáles de los siguientes dispositivos ha usado para acceder a noticias en la última semana? Posibilidad de respuesta múltiple. Se muestran combinadas (Base: 2.017 usuarios en España)

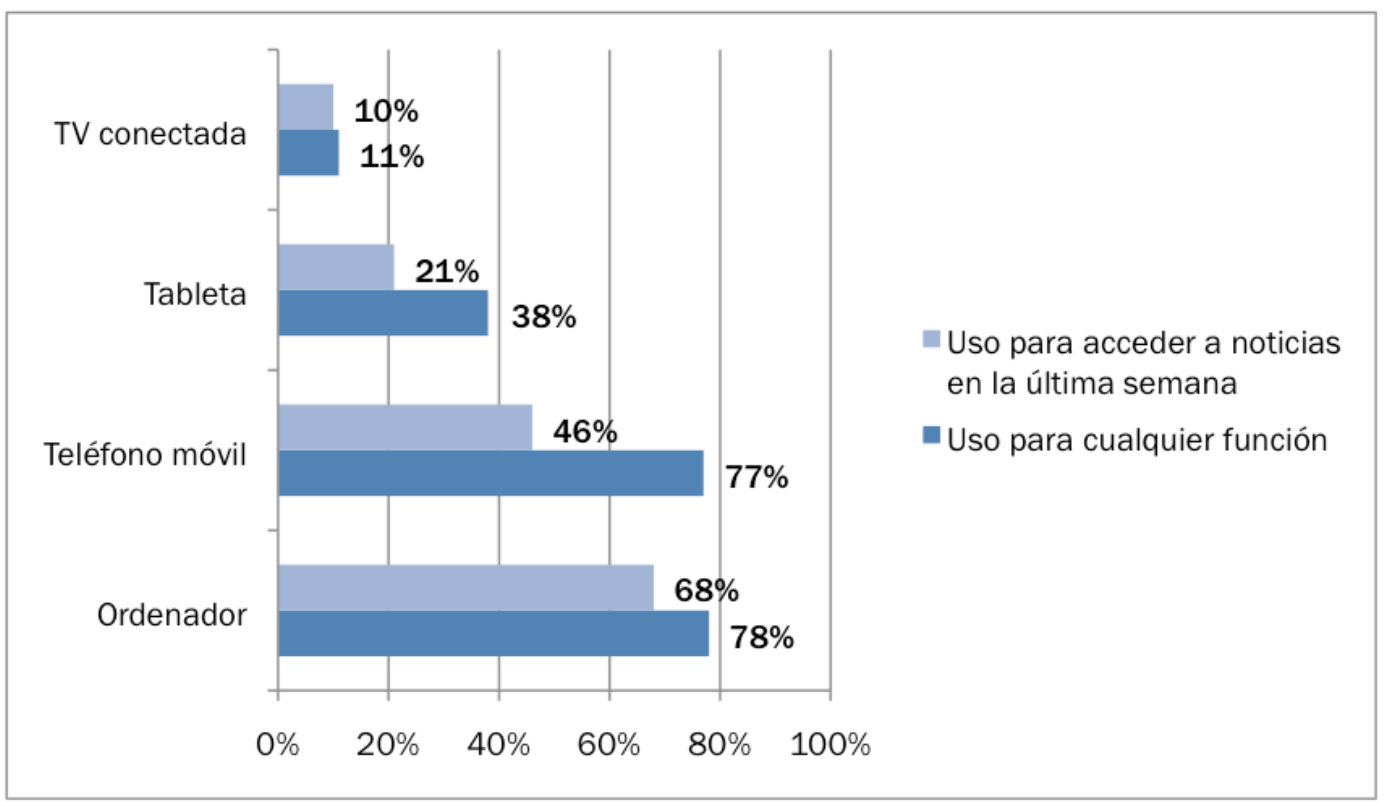


En España, consulta las noticias mediante el ordenador el $\mathbf{8 7 \%}$ de quienes lo emplean por cualquier motivo; es decir, un $68 \%$ del total de usuarios de internet que ven o leen noticias de alguna forma. La situación es distinta con los teléfonos móviles: entre quienes hacen uso de ellos, los emplea para informarse el 57\%; esto supone el $44 \%$ de los internautas españoles encuestados. Conviene segmentar por marcas: un $75 \%$ de usuarios españoles de iPhone lo emplea para seguir la actualidad ( $9 \%$ del total de la población conectada y consumidora de noticias), frente al $\mathbf{5 8 \%}$ de usuarios de otras marcas de teléfonos inteligentes distintas de Apple (36\% de la población española adulta, con acceso a internet y que se informa).

Hay un $21 \%$ de los encuestados que consulta las noticias en tableta, lo que supone el $55 \%$ de quienes emplean uno de estos dispositivos táctiles por cualquier motivo. De nuevo, hay variaciones según la marca: un $62 \%$ de los usuarios de iPad accede a información periodística a través de este dispositivo ( $8 \%$ del total de encuestados), mientras que sólo al $\mathbf{4 8 \%}$ de las personas que utilizan tabletas de marcas alternativas a Apple les sirve este dispositivo para informarse de lo que ocurre en el mundo.

¿Cuál es su dispositivo principal para acceder a las noticias en internet? Respuesta única (Base: 1.810 usuarios en España)

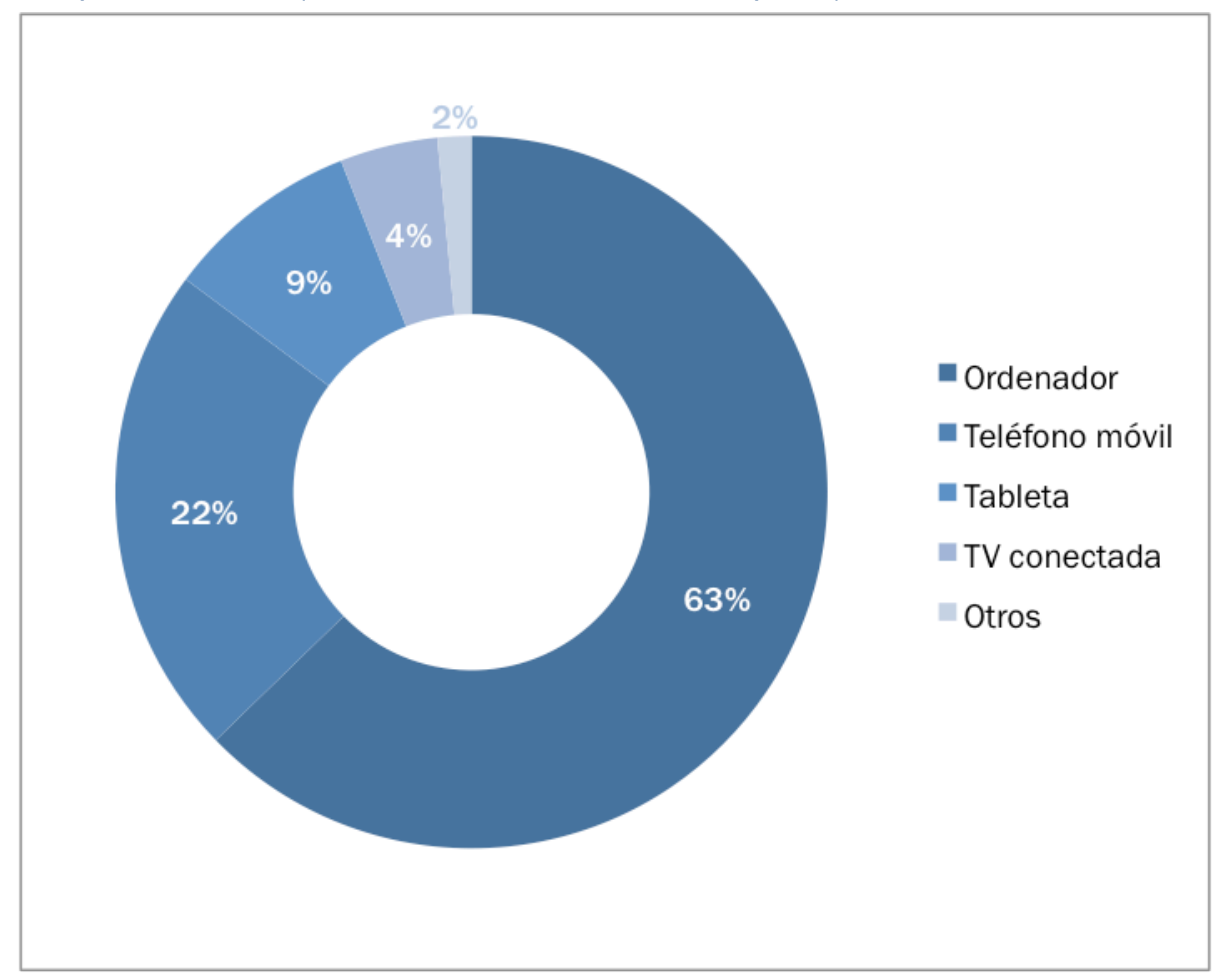

El ordenador de sobremesa o portátil sigue siendo el dispositivo principal de acceso a noticias en internet, en casa o en el trabajo, en todos los países estudiados. El $63 \%$ de usuarios de España que siguen la actualidad, sobre todo, desde su ordenador, es inferior a la cuota de este dispositivo en Italia y Estados Unidos (ambos 69\%), Finlandia (74\%) o Japón (79\%), pero superior a la del resto de países europeos: Dinamarca (54\%) y Reino Unido (57\%) marcan los mínimos, seguidos de Alemania (60\%), Francia (61\%) y, ya fuera del continente, Brasil (62\%).

En el contexto global de la encuesta, un $20 \%$ de usuarios se informa prioritariamente a través del teléfono móvil. España está dos puntos por encima, con un $22 \%$ que iguala el dato de Francia. En España un 9\% se informó a través de un iPhone, y el 36\% en teléfonos de otras marcas. Los países con mayor adopción del móvil como principal dispositivo de acceso a 
noticias son Reino Unido, Alemania y Dinamarca, con un $\mathbf{2 4 \%}$. Por debajo de la media quedan Italia (19\%), el Brasil urbano (18\%), Estados Unidos (17\%) y Finlandia y Japón (15\% en ambos).

Las tabletas se han convertido en el soporte preferido para informarse del $10 \%$ del total de encuestados en los diez países. España (9\%) está apenas un punto porcentual por debajo de esta media, con los mismos datos que Alemania y Finlandia. En el mercado que nos ocupa, Francia, Italia y el Brasil urbano, con el 8\%, quedan otro punto por debajo. En Japón, los que prefieren el móvil todavía quintuplican a los que eligen la tableta (3\%). Dinamarca es el país donde más usuarios, en proporción, eligen la tableta en primer lugar para acceder a noticias, con un $18 \%$, sólo seis puntos menos que los que se informan en ese país principalmente a través del móvil. A continuación viene Reino Unido (16\%) y ya en la media, EE. UU. (10\%).

\section{LOS USUARIOS SIGUEN PRIORIZANDO EL ORDENADOR, PERO}

\section{EL MÓVIL YA ES EL PRINCIPAL DISPOSITIVO DE ACCESO A LAS NOTICIAS PARA CUATRO DE CADA DIEZ MENORES DE 35 AÑOS}

¿Cuál es su dispositivo principal para acceder a las noticias en internet?

Respuesta única (Base: 1.806 usuarios en España)

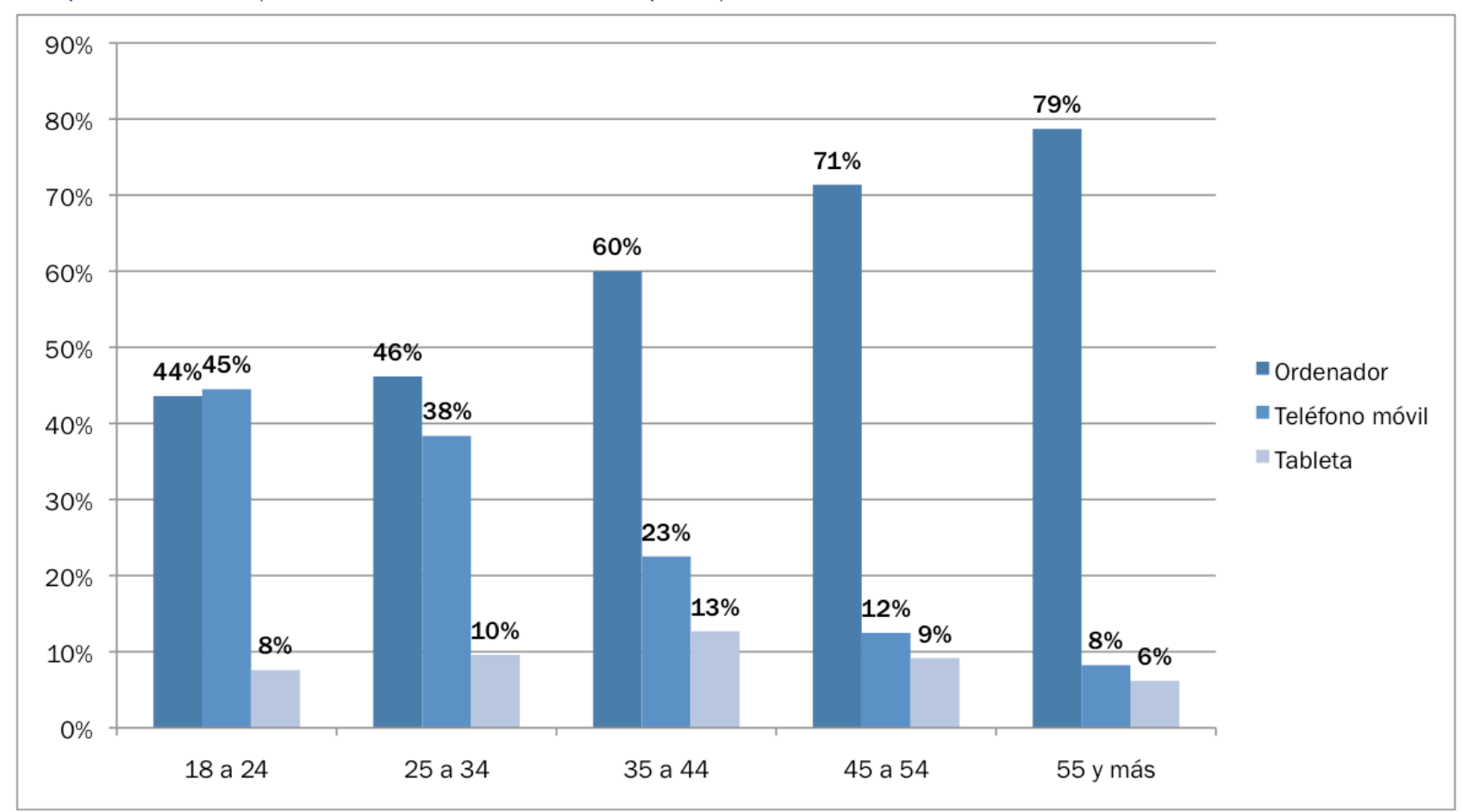

Los teléfonos móviles inteligentes sobrepasan al ordenador como soporte prioritario para seguir la actualidad sólo en la franja de adultos menores de $\mathbf{2 5}$ años, y por la mínima. Se observa la correlación directa entre la edad y el uso del ordenador en primer lugar para informarse, y la inversa entre la edad y elegir primero el teléfono para consumir noticias. Las tabletas se hacen un hueco, sobre todo, entre los usuarios de 35 a 44 años, pero debido al menor uso del teléfono, están más cerca de desbancarlo en las franjas superiores de edad.

Finalmente, se puede apuntar que el ordenador es el dispositivo principal para informarse para un $65 \%$ de hombres frente a un $61 \%$ de mujeres, mientras que las usuarias de noticias eligen en proporción ligeramente superior los teléfonos móviles inteligentes $(23 \%$ frente a $22 \%$ ) y las tabletas: $10 \%$, dos puntos por encima de los $8 \%$ de los usuarios hombres. 


\section{EL 8,5\% PAGA POR NOTICIAS 'ONLINE'. ENTRE LOS DEMÁS, UN 21\% VE PROBABLE HACERLO}

- Un $25 \%$ de hombres españoles entre 25 y 34 años que se informan en internet ha pagado por información 'online' alguna vez en el año

- La menor predisposición al pago entre los usuarios de España se da entre los que acceden a noticias por ordenador, con un $7 \%$

\section{- Entre quienes acceden a noticias en iPhone, o desde cuatro o más dispositivos, hay un 24\% que pagó por ellas en el último año}

En España, asegura que compró un periódico impreso en la última semana un $57 \%$ de los encuestados (recordemos: usuarios de internet que emplearon este modo de acceso para consumir noticias en el último mes), en una proporción similar a la registrada en Italia, Alemania y el Brasil urbano, e inferior a la de Japón, pero que sorprende en comparación con Reino Unido (49\%), Finlandia (41\%), Francia (40\%), Estados Unidos (39\%) o Dinamarca (30\%).

El dato en España se reduce al 48\% (baja 9 puntos porcentuales) entre los adultos menores de 25 años, y se eleva al 62\% al preguntar a los mayores de 55. El 49\% del total de encuestados había adquirido el diario en un quiosco o una tienda; el 6\% lo recibió en su domicilio, y un $5 \%$ lo obtuvo por otras vías (las opciones no eran excluyentes entre ellas). Hay más compradores de prensa en soporte papel entre los hombres (63\%) que entre las mujeres (50\%).

\section{UNO DE CADA CUATRO HOMBRES ESPAÑOLES ENTRE 25 Y 34 AÑOS ASEGURA HABER PAGADO POR NOTICIAS EN INTERNET EN EL ÚLTIMO AÑO, PERO LA MEDIA GENERAL ES DEL 8,5\%}

Sólo el 8,5\% de los usuarios españoles que se informan en internet pagó por noticias digitales en el último año, frente a un $90 \%$ que reconoce no haber efectuado ningún desembolso por la información que consumió en la red. Un 1,5\% no lo sabe o no lo recuerda.

Hay variaciones importantes según los dispositivos de acceso empleados y los factores demográficos; comencemos por estos últimos el análisis detallado. Dice haber pagado por información en internet un $11 \%$ de hombres frente al $6 \%$ de mujeres. Las diferencias son especialmente acusadas en la franja de edad en la que el pago presenta mayor índice de aceptación, la de usuarios entre 25 y 34 años: en conjunto se alcanza un 15\% de personas que han pagado por las noticias en internet, dato que esconde una cuota del $25 \%$ entre los hombres, uno de cada cuatro, y un $7 \%$ entre las mujeres, según los resultados de la encuesta.

En la franja de edad inmediatamente inferior, adultos hasta 24 años, hay un 14\% de hombres que pagaron por noticias, frente al $5 \%$ de mujeres, casi la tercera parte. En la franja de hombres entre 35 y 44 años, el porcentaje de usuarios que han adquirido información digital es del 10\%. En ningún subgrupo por sexo y franja de edad baja del $5 \%$ la cuota de usuarios que ha pagado por noticias en internet. 
¿Ha pagado por acceder a contenidos de noticias en línea, o ha accedido a un servicio de noticias en línea de pago durante el último año (por ejemplo, mediante una suscripción o realizando un pago por un artículo o aplicación)?

Porcentaje de respuestas afirmativas (Base: 18.836 encuestados en diez países)

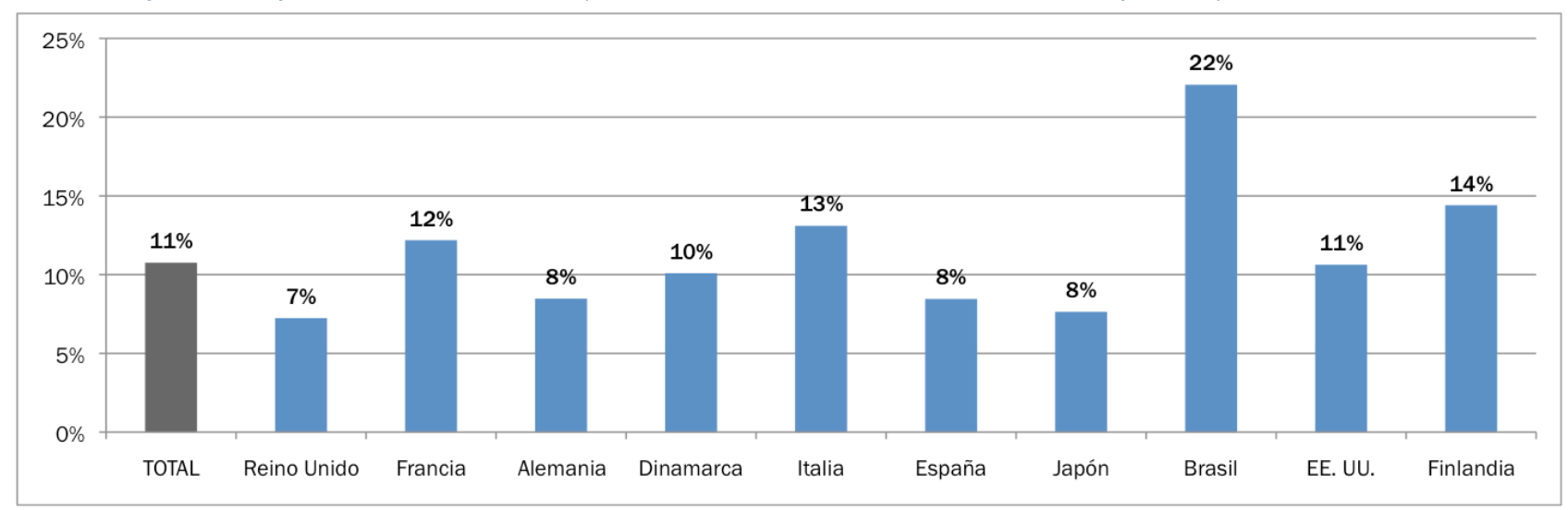

En el conjunto de la encuesta, el resultado global es de un 11\% de usuarios de pago; España se encuentra entre los países de cola, junto con Reino Unido, Alemania y Japón, mientras que esta modalidad es más fuerte en países nórdicos como Finlandia, pero también en otros mediterráneos como Italia o Francia, que se sitúan ligeramente por encima de la media. En cualquier caso, destacan las zonas urbanas de Brasil, que duplican el resultado total.

\section{ENTRE LOS SEIS DE CADA DIEZ USUARIOS ESPAÑOLES QUE ACCEDEN A LAS NOTICIAS PRINCIPALMENTE A TRAVÉS DEL ORDENADOR, APENAS UN 7\% HA PAGADO EN EL ÚLTIMO AÑO}

Por dispositivos, entre los encuestados españoles, en el último año pagaron por información periodística el $24 \%$ de quienes emplearon un iPhone para acceder a noticias en internet en la semana previa a la encuesta (aunque éste no fuera su modo de acceso principal), y el $18 \%$ de quienes emplearon un iPad. Entre quienes accedieron a la actualidad a través de su teléfono móvil inteligente de otras marcas, sólo pagó a los proveedores de noticias un 9\%. En cuanto a tabletas de otras marcas, la cuota de usuarios que pagaron por noticias se situó en el 14\%.

Los usuarios más proclives a comprar contenidos informativos en medios digitales, ya sea adquiriendo una suscripción, una aplicación o el acceso a un contenido concreto, son quienes emplean principalmente el iPad para informarse en internet: un $20 \%$ de estas personas había pagado por noticias digitales en el último año. El porcentaje más bajo corresponde a los usuarios que acceden a las noticias principalmente a través de un ordenador (ya sea portátil o de sobremesa; en casa o el trabajo). En este grupo, que es el mayoritario (61\% de todos los encuestados), sólo un 7\% había pagado por informarse en internet en el último año.

Según los resultados de la encuesta, en España hay un 3\% de usuarios que utilizan cuatro o más dispositivos para acceder a noticias a través de internet. En este grupo, nada menos que un $\mathbf{2 4 \%}$ había pagado por ellas en algún momento en el último año, lo que supone tres veces la media. También hay un $11 \%$ de usuarios de internet que se conectan para informarse desde tres dispositivos distintos, y entre ellos pagó por noticias un 12\%, un 50\% más que la media. 


\section{CASI LA MITAD DE LOS USUARIOS QUE HAN PAGADO POR CONTENIDOS INFORMATIVOS TIENEN UNA SUSCRIPCIÓN, Y} SEIS DE CADA DIEZ HAN REALIZADO UNA COMPRA PUNTUAL

De ese escaso 8,5\% de usuarios encuestados que pagó por noticias en medios digitales, lo más habitual fue realizar una transacción puntual: comprar un artículo o un archivo PDF, un acceso de un día, una aplicación o un número en un quiosco digital; un $61 \%$ de los usuarios que pagaron lo hicieron en alguna de estas modalidades de pago único. Las suscripciones de cualquier tipo, ya fueran únicamente digitales o combinadas con otros servicios de información o comunicación, de manera que suponían un pago regular, correspondieron al $47 \%$ de usuarios de pago. Por tanto, algunos encuestados adquirieron noticias en ambas modalidades.

¿Cuáles de los siguientes métodos de pago ha usado para poder acceder a contenidos de noticias en línea durante el último año?

Posibilidad de respuesta múltiple (Base: 171 usuarios españoles que pagaron en el último año)

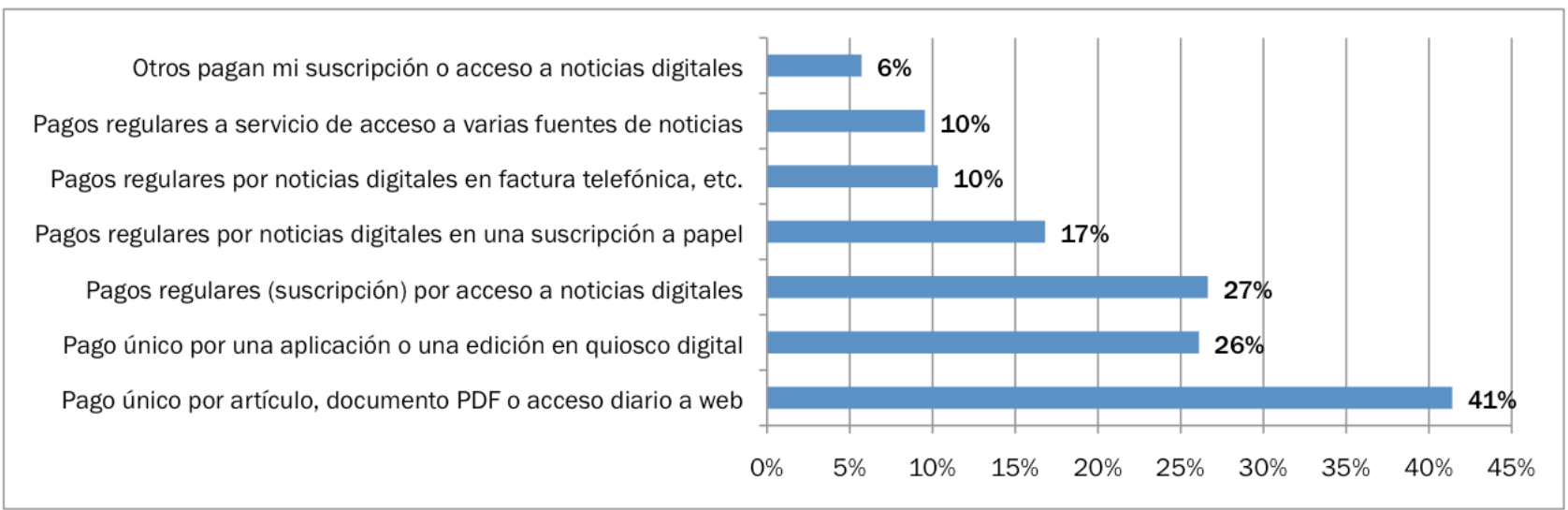

Entre el escaso $4 \%$ de usuarios de internet que pagaban una suscripción en el momento de la encuesta, las principales cabeceras informativas a las que se habían abonado en el último año para tener acceso digital continuo eran El Mundo (35\%), El País (27\%) y Marca (17\%).

Dentro del $5 \%$ del total de encuestados que había realizado uno o varios pagos únicos para acceder a noticias digitales, los principales periódicos receptores de estas transacciones puntuales fueron, de nuevo, El Mundo (25\%), El País (20\%) y Marca (13\%).

¿Cuáles de los siguientes métodos de pago ha usado para poder acceder a contenidos de noticias en línea durante el último año? Posibilidad de respuesta múltiple

(Base: 2.027 usuarios que dicen haber pagado en el último año entre los diez países)

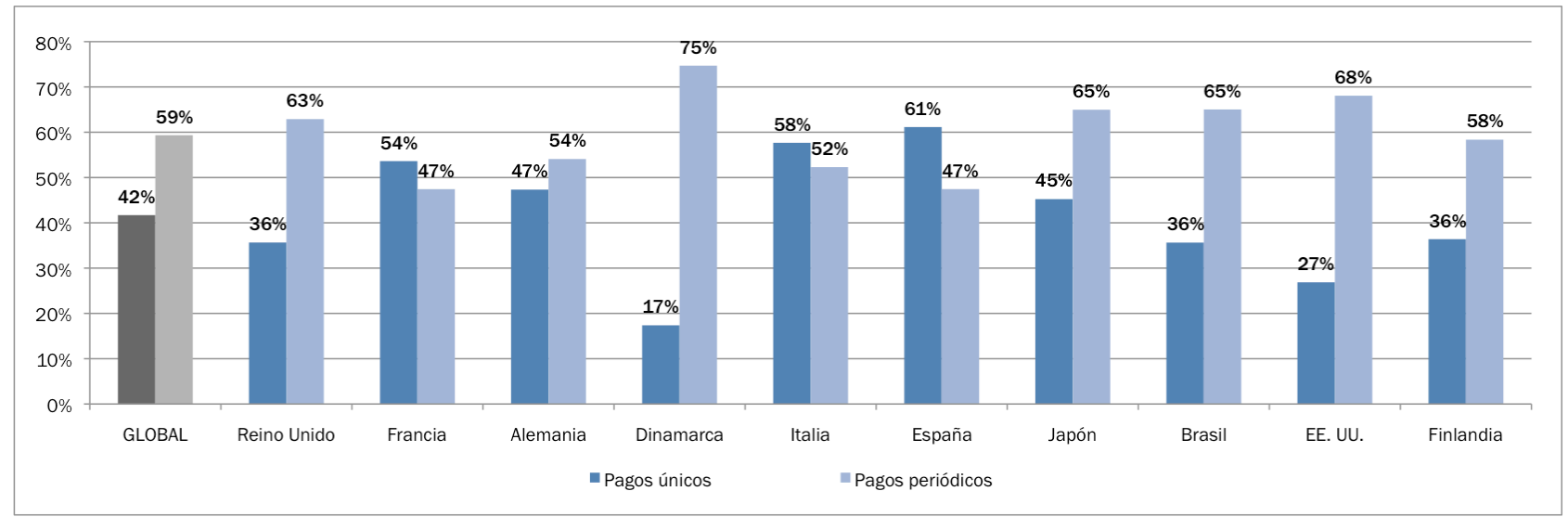




\section{CUATRO DE CADA DIEZ USUARIOS QUE COMPRAN NOTICIAS DIGITALES ADQUIEREN UN ACCESO PUNTUAL, Y UNO DE CADA CUATRO PAGA POR EDICIONES Y APLICACIONES DE MEDIOS}

España también es un mercado atípico en cuanto a las modalidades de pago predominantes. Si nos ceñimos a los resultados de la encuesta, es el país en que, entre los usuarios de pago, una proporción mayor efectuó pagos individuales para acceder de forma puntual a un artículo, un sitio web (por ejemplo, un pase diario) o un archivo PDF: un 41\% de los usuarios de pago españoles adquirió información de este modo, frente a la media global del $27 \%$. Esta modalidad de pago puntual por representa apenas el 19\% en Estados Unidos, un 22\% en Reino Unido y un 27\% en Alemania. Más similares a España en este sentido son Francia (31\%) e Italia (34\%).

En pagos puntuales por aplicaciones y descarga de ediciones individuales en quioscos digitales, con un 26\%, España también está por encima de la media global (20\%), y dentro del grupo formado por Alemania (24\%), Francia (28\%) e Italia (30\%). Esta forma de transacción es menos habitual en Estados Unidos (10\%), Reino Unido (15\%), y los países nórdicos (6\%-16\%).

Las cosas cambian si nos fijamos en los pagos periódicos: las suscripciones a servicios digitales de noticias, con pago periódico, suponen apenas un $27 \%$ en España, ocho puntos por debajo de la media global (35\%). Este compromiso económico continuado con la información en línea se da principalmente en el Reino Unido (47\% de los usuarios de pago), Dinamarca (42\%) y Estados Unidos (40\%). En los grandes países de la Europa continental, oscila entre el 31\% de Francia, y el 35\% de Italia, pasando por el 33\% de Alemania.

Aunque no conviene desdeñar los pagos por aplicaciones, ediciones o acceso puntual, hay que tener en cuenta que, mientras que en muchos países las ofertas digitales se promocionan por días, semanas o meses -a menudo, con un precio inicial más bajo-, los diarios con más usuarios de pago en España han lanzado de forma recurrente promociones en las que ofrecen grandes descuentos a quienes realizan un solo desembolso que les proporciona acceso para todo el año; es decir, el equivalente de una suscripción, tanto en servicios suministrados como en el compromiso económico y de permanencia que supone para el usuario, pero en un pago.

España se acerca a la media, con un $\mathbf{1 7 \%}$ (el dato global es del 19\%), en pagos periódicos por acceso digital como parte de una suscripción a una publicación impresa. Supera a los principales mercados europeos: en Francia y Alemania, 12\%; en Italia alcanza el 13\%, y en Reino Unido esta suscripción combinada llega al 16\% de los usuarios de pago. Sin embargo, en los mercados nórdicos estudiados esta fórmula disfruta de mayor popularidad: un $29 \%$ en Finlandia y un 31\% en Dinamarca. También en Estados Unidos, con un 23\% de usuarios que acceden a información de pago en internet como parte de su suscripción al diario impreso.

ENTRE QUIENES PAGAN, ESPAÑA ES EL PAÍS EUROPEO CON MÁS ÉXITO DE LOS SERVICIOS QUE DAN ACCESO A VARIOS MEDIOS, Y ENCABEZA EL ABONO VÍA FACTURA TELEFÓNICA

Hay que destacar dos modalidades de pago, más minoritarias en comparación con la suscripción sólo digital y la combinada con medios impresos, pero que también suponen una parte significativa del mercado de pago por noticias digitales en España. 
En el mercado español, en el alemán y en el italiano, un $10 \%$ de los usuarios que pagan por noticias digitales especifican que realizan el abono a través de la factura de su proveedor de telecomunicaciones. Es un 7\% en Estados Unidos, un 6\% en Francia y un 4\% en Reino Unido. A juzgar por los resultados de la encuesta, esta fórmula es más habitual en Japón (14\%) y las zonas urbanas de Brasil (21\%), y menos en los países nórdicos (5\% en Finlandia y Dinamarca).

España es también el país de Europa en el que más usuarios pagan por un servicio que les facilita el acceso simultáneo a varias publicaciones o fuentes de noticias. La cuota de mercado de esta modalidad entre los usuarios españoles de noticias digitales de pago es del $10 \%$, frente al $8 \%$ de Francia y Alemania, el $6 \%$ de Estados Unidos e Italia, el $4 \%$ de Finlandia y Dinamarca y el $2 \%$ del Reino Unido.

\section{UNO DE CADA CINCO USUARIOS QUE NO PAGAN AHORA POR NOTICIAS EN MEDIOS DIGITALES SÍ CONSIDERA PROBABLE HACERLO EN EL FUTURO; ES UN 28\% ENTRE MENORES DE 35}

El $43 \%$ de los usuarios que no pagan ahora por noticias en internet descarta por completo pagar por ellas en el futuro. A esta opción mayoritaria se suma un $29 \%$ de usuarios que no pagan en la actualidad y que consideran "bastante improbable" hacerlo en el futuro.

Sólo un 3\% de los encuestados que no pagan actualmente por noticias digitales afirma que es "muy probable" que se conviertan en clientes de pago de un servicio de noticias en internet próximamente, pero un 18\% lo considera "bastante probable". Estas opciones, que suman un $\mathbf{2 1 \%}$ de usuarios, se dan en medida algo mayor entre los usuarios menores de 35 años.

Ha dicho que no ha pagado por contenidos digitales en el último año. ¿Qué probabilidad hay de que pague en el futuro por noticias en línea de determinadas fuentes que le gustan? Respuesta única (Base: 1.817 usuarios que dicen no haber pagado en el último año)

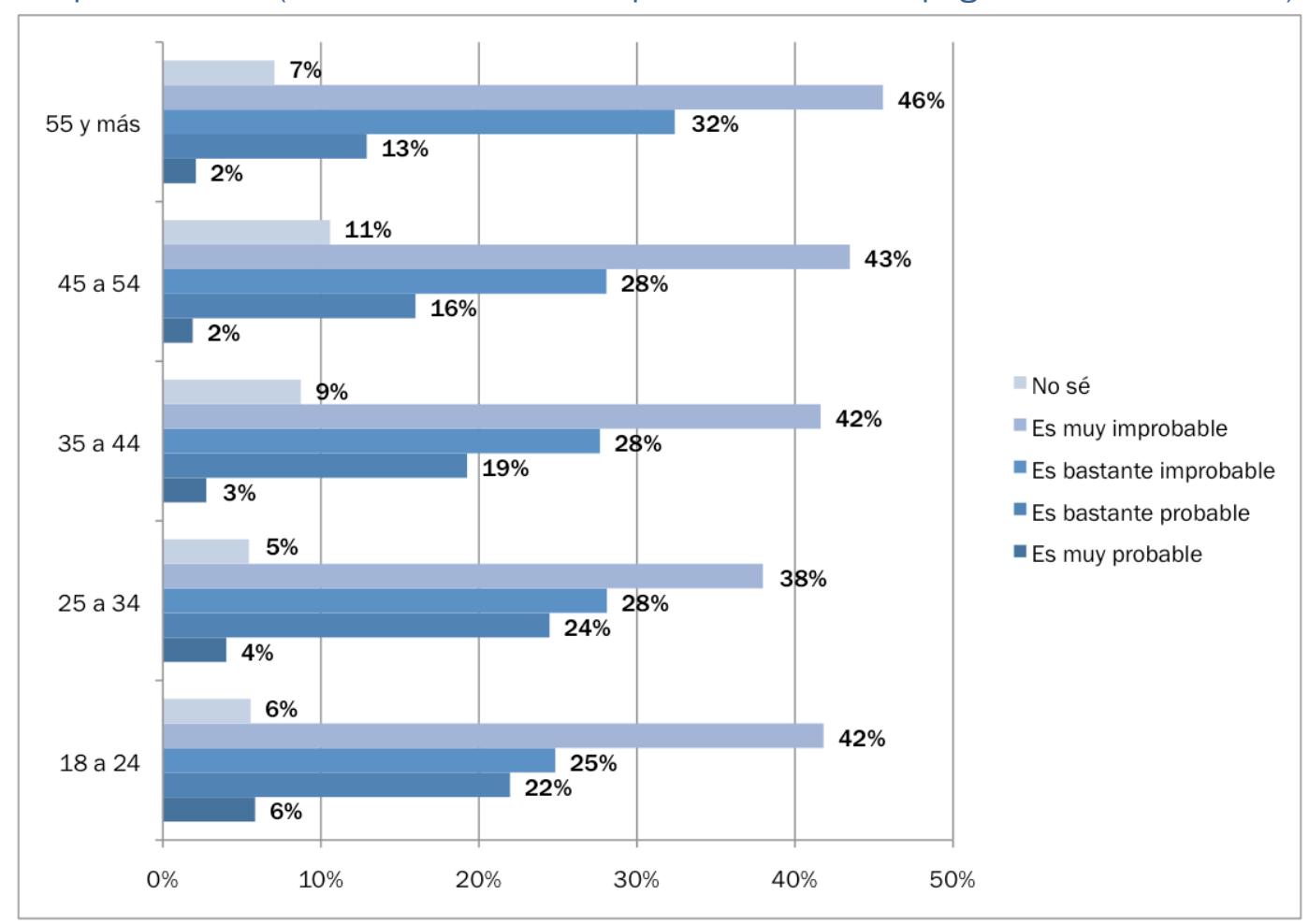


Si nos fijamos en los resultados globales, en el conjunto de países estudiados un $15 \%$ de usuarios que no pagan considera "bastante" o "muy" probable pagar en el futuro. España, con el $21 \%$, es el tercer país de los diez estudiados con más proporción de usuarios que ven probable pagar por noticias en internet en el futuro aunque no lo hayan hecho todavía. Todo ello, pese a que es el tercer mercado por el final en cuanto a usuarios que han pagado en el último año.

Menos sorprendentes son los datos de Estados Unidos y Japón, los dos países con menos usuarios de pago, que se sitúan igualmente a la cola en cuanto a la proporción de actuales usuarios gratuitos que ven probable pagar en el futuro: un $7 \%$ y un $8 \%$, respectivamente. Mientras que en España los usuarios que ven probable pagar en el futuro son proporcionalmente más del doble que los que pagan en la actualidad, en Reino Unido y Japón el porcentaje apenas iguala al de usuarios de pago actuales sobre el total de usuarios.

En esta declaración de intenciones, España queda en tercer lugar, sólo por detrás del Brasil urbano, con un muy alto $61 \%$ que lo considera bastante o muy probable (casi el triple que los actuales), e Italia, con un $23 \%$ de potenciales usuarios de pago, dos puntos porcentuales por encima de España (pero en Italia la proporción de los que lo ven probable en el futuro no llega a duplicar la proporción de usuarios de pago actuales).

A excepción de Alemania, que se sitúa justo en la media (15\%, casi el doble que los que pagan en la actualidad), el resto de países -Francia, Estados Unidos, Dinamarca y Finlandia- arroja resultados del $10 \%$ o el $11 \%$ de usuarios que ven bastante o muy probable pagar en el futuro, bastante similares a la proporción de usuarios de pago actuales sobre el total. 


\section{LA AUDIENCIA WEB PREFIERE LOS TITULARES Y PRIORIZA EL TEXTO SOBRE LO MULTIMEDIA}

- Más de la mitad del público 'online’ español mira portadas; el $40 \%$ lee noticias y artículos. Los vídeos Ilegan a un usuario de cada seis

- Un $19 \%$ ve al menos una fotogalería por semana; el $12 \%$ sigue las crónicas minuto a minuto, y un $11 \%$ lee blogs sobre las noticias

\section{- Uno de cada ocho internautas consulta noticias en aplicaciones descargadas a su dispositivo: el 10\% en móvil y el 5\% en tableta}

El $73 \%$ de los usuarios de internet consume información digital en formatos escritos (titulares, noticias o blogs) al menos una vez a la semana. Exactamente un tercio (33\%) escucha audios o ve vídeos informativos 'online', y en total el $23 \%$ mira fotografías o gráficos. No hay grandes diferencias por grupos demográficos en el consumo de los distintos formatos de información.

Piense en la forma en la que ha visto las noticias en línea durante la última semana; ¿de qué formas ha consumido las noticias? Posibilidad de respuesta múltiple (Base: 2.017 usuarios en España)

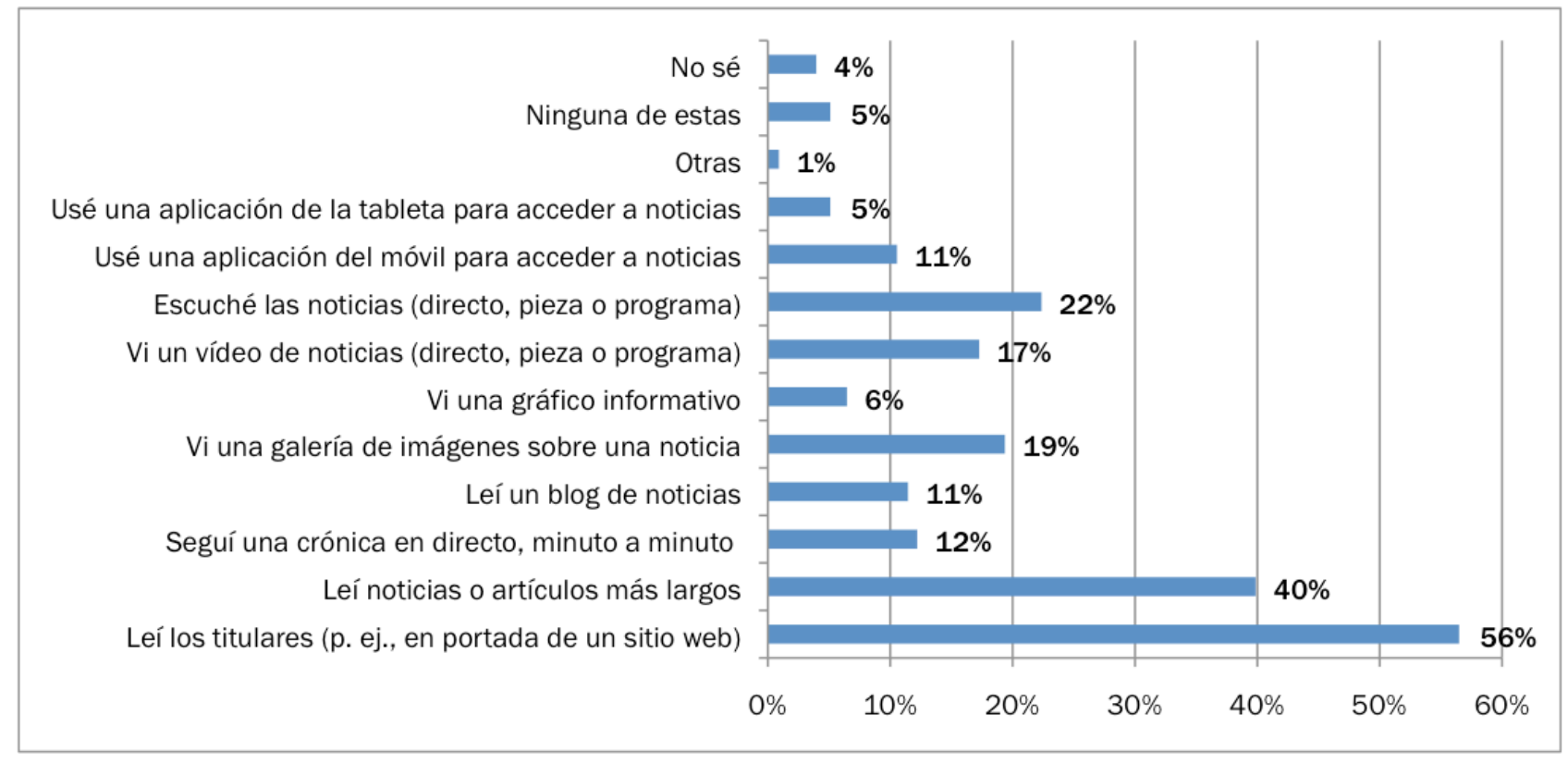

La lectura de titulares - por ejemplo, en las páginas principales de los sitios web-, que permite conocer la actualidad del momento de forma superficial, es la actividad más común en ocho de los países estudiados, con un 58\% (dos puntos más que en España). Un 40\% de los usuarios españoles que se informan en internet lee noticias o artículos más largos, una proporción ligeramente inferior a la de Reino Unido (43\%), Francia (44\%) o Estados Unidos (45\%), y cinco puntos por debajo del resultado global en los diez países de la encuesta. El seguimiento en texto en vivo, minuto a minuto, que se emplea habitualmente en muchos medios españoles para noticias de última hora, acontecimientos políticos y eventos deportivos, 
sólo es más popular que en España (12\%) entre los italianos (15\%). En el resto de países europeos, accede a información de este tipo entre el $6 \%$ y el $8 \%$ de los usuarios.

Los blogs, un formato de información y análisis ya clásico de internet, atraen a un 11\% de usuarios de noticias 'online' españoles, lo que los sitúa justo en la media global. Su seguimiento oscila entre el 7\% y el $8 \%$ en Reino Unido, Francia y Alemania; es apenas del 5\% o $6 \%$ en países nórdicos como Dinamarca y Finlandia, pero se dispara al 18\% en Estados Unidos y al $20 \%$ en Italia.

El uso de aplicaciones para teléfonos móviles (10\%) y tabletas (5\%) en España se sitúa en la media del conjunto de países, así como el total de uso de aplicaciones en cualquiera de los dos dispositivos mencionados: un $13 \%$ en este mercado y en el conjunto de los diez países.

En cuanto a los formatos audiovisuales, un $17 \%$ de usuarios españoles dice haber visto un vídeo de actualidad en internet en la última semana; es una proporción ligeramente superior a la de Reino Unido y Alemania (16\%) y Francia (15\%), pero inferior a la de Finlandia (18\%), Italia (20\%) o Estados Unidos, donde quienes se informan con vídeos alcanzan el 30\% de la audiencia de noticias en internet. El gráfico inferior muestra por qué los usuarios españoles no suelen ver vídeos de noticias 'online', una pregunta planteada sólo en algunos países: en un $22 \%$ de los casos, se trata de motivos técnicos, pero sobre todo se señalan cuestiones de preferencia personal, ya sea por el formato (un 38\% prefiere leer artículos) o por el dispositivo.

Las galerías fotográficas presentan una popularidad algo mayor, del 19\% en España, entre tres y cinco puntos superior a la que se da en el resto de países europeos, e igual a la que tienen las secuencias de fotos en Estados Unidos. Los gráficos atraen a un 6\% de usuarios en España, un dato homologable con el de otros países europeos como Reino Unido (4\%), Francia (5\%) o Alemania (7\%), pero muy inferior al de mercados como Estados Unidos (un $10 \%$ de usuarios ve gráficos) o Japón (un 14\%).

España es el país en el que una proporción mayor de usuarios asegura escuchar audios en internet, ya sean en directo o a la carta: un $22 \%$, el doble de la media en el conjunto de países estudiados. El siguiente mercado en consumo de sonido 'online' es ya Italia, con un $17 \%$.

Ha dicho que no suele ver vídeos de noticias en internet. ¿Por qué no?

Posibilidad de respuesta múltiple

(Base: 1.669 usuarios en España que no habían visto un vídeo en la última semana)

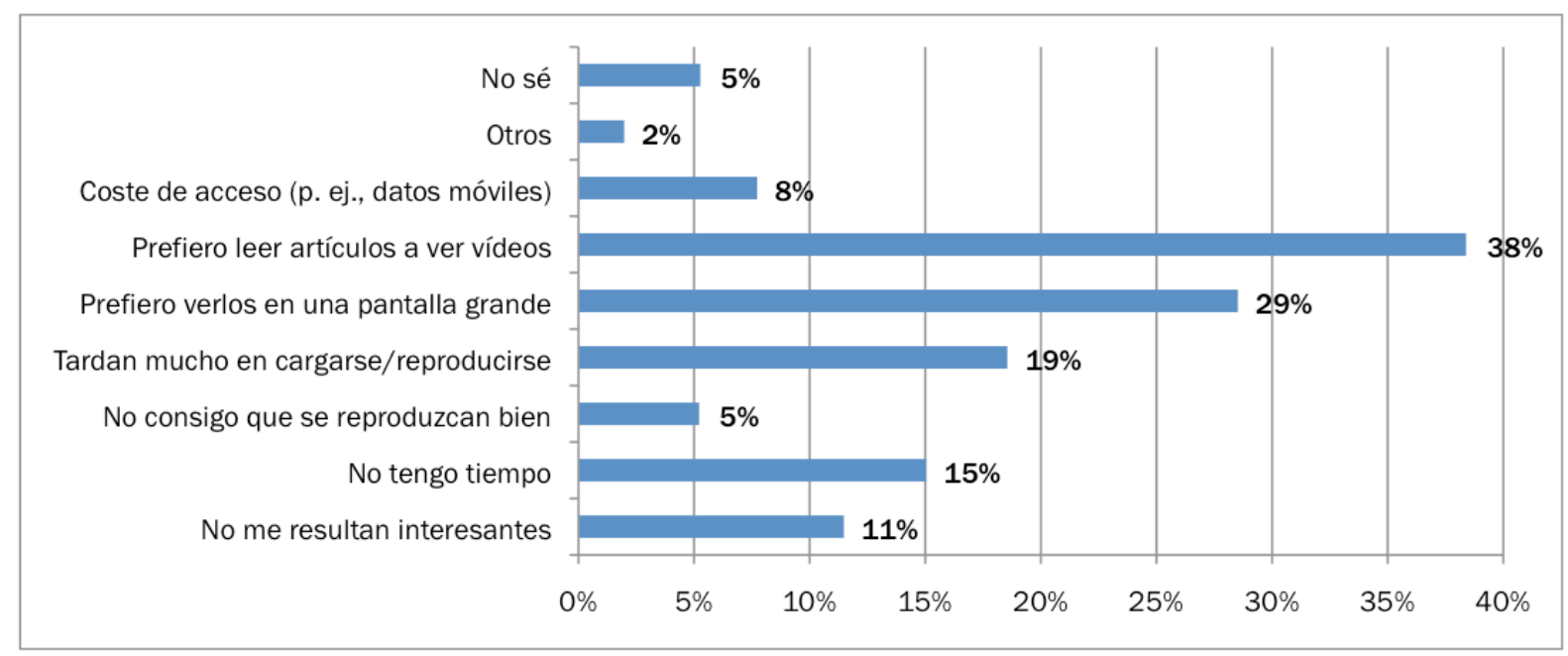


¿Qué tipos de vídeos de noticias ha visto por internet durante el último mes?

Posibilidad de respuesta múltiple

(Base: 348 usuarios de España que habían visto un vídeo en la última semana)

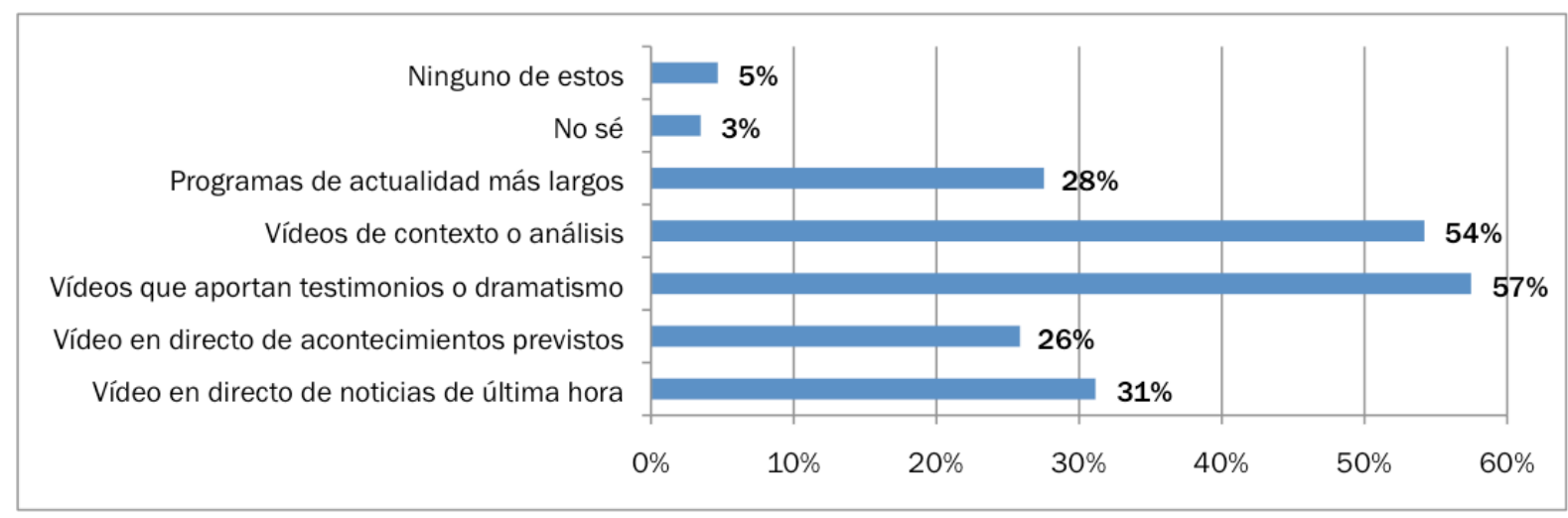

Los datos agregados muestran que, entre los usuarios españoles que habían visto un vídeo en la última semana, el $78 \%$ accedió bajo demanda a un clip editado (gran equilibrio por sexos y edades), y el $44 \%$ conectó con una emisión en directo, con una audiencia más masculina (49\%) que femenina (36\%). En cuanto a las preferencias entre texto y vídeo, predomina el formato escrito, como se puede ver a continuación; todavía son muy escasos los usuarios que prefieren informarse 'online' principalmente en formato audiovisual. En este caso, no hay diferencias importantes por grupos demográficos.

Piense en sus hábitos de consumo de noticias por internet; ¿cuál de los siguientes enunciados se corresponde mejor con usted? Respuesta única (Base: 2.017 usuarios en España)

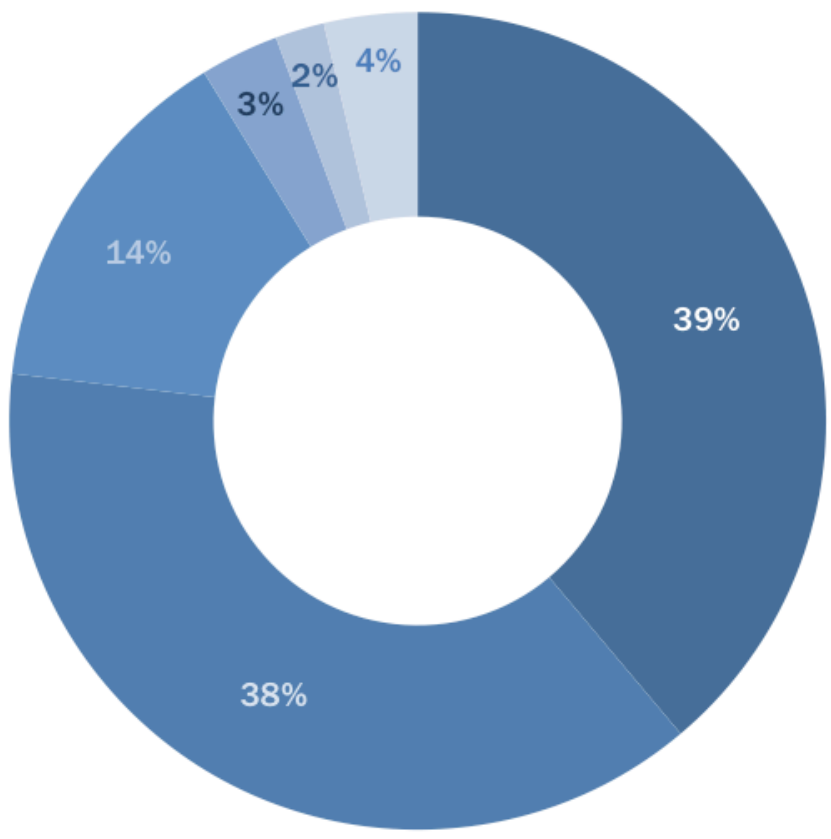

- Principalmente leo noticias en formato texto

- Principalmente en texto, pero a veces en vídeo

- Leo noticias en texto y las veo en vídeo indistintamente

- Principalmente en vídeo, pero a veces en texto

Principalmente veo vídeos de noticias

No sé 


\section{LOS USUARIOS EN ESPAÑA, ENTRE LOS QUE MÁS PARTICIPAN, Y MUCHOS DAN LA CARA}

- La mitad de los usuarios del Estado comentan las noticias con
amigos y compañeros cara a cara; uno de cada cuatro, por internet

- Los usuarios españoles superan ampliamente la media global en todas las formas de participar, excepto en comentarios en medios

- Un $21 \%$ dice haber contribuido a un sitio de noticias con nombre y apellido. El 16\%, con usuario reconocible. Hay un 11\% de anónimos

En el conjunto de países en los que se realizó la encuesta, un 33\% de usuarios no participa ni comparte noticias de ninguna de las maneras sugeridas en una semana normal. En Francia y Reino Unido, la tasa de lectores pasivos llega a ser de 4 de cada 10, mientras que en territorio español apenas uno de cada seis usuarios de información online no hace nada con ella. En España, entre los que consultan noticias en internet, sólo un 10\% de jóvenes entre 18 y 24 años no comparte noticias ni participa en ellas de ninguna de estas maneras; la media global sube al $28 \%$. El porcentaje de consumidores de información 'online' que no la comparten ni participan en ella va creciendo por franjas de edad: 13\% de usuarios entre 25 y 34 años; $15 \%$ de 35 a 44 años; 17\% de 45 a 54 años, y 21\% a partir de 55 años (frente a la media del 36\%).

En una semana normal, ¿cómo suele compartir o participar en la cobertura de noticias?

Admitidas respuestas múltiples (Base: 2.017 usuarios en España y 18.837 u. en el conjunto de países)

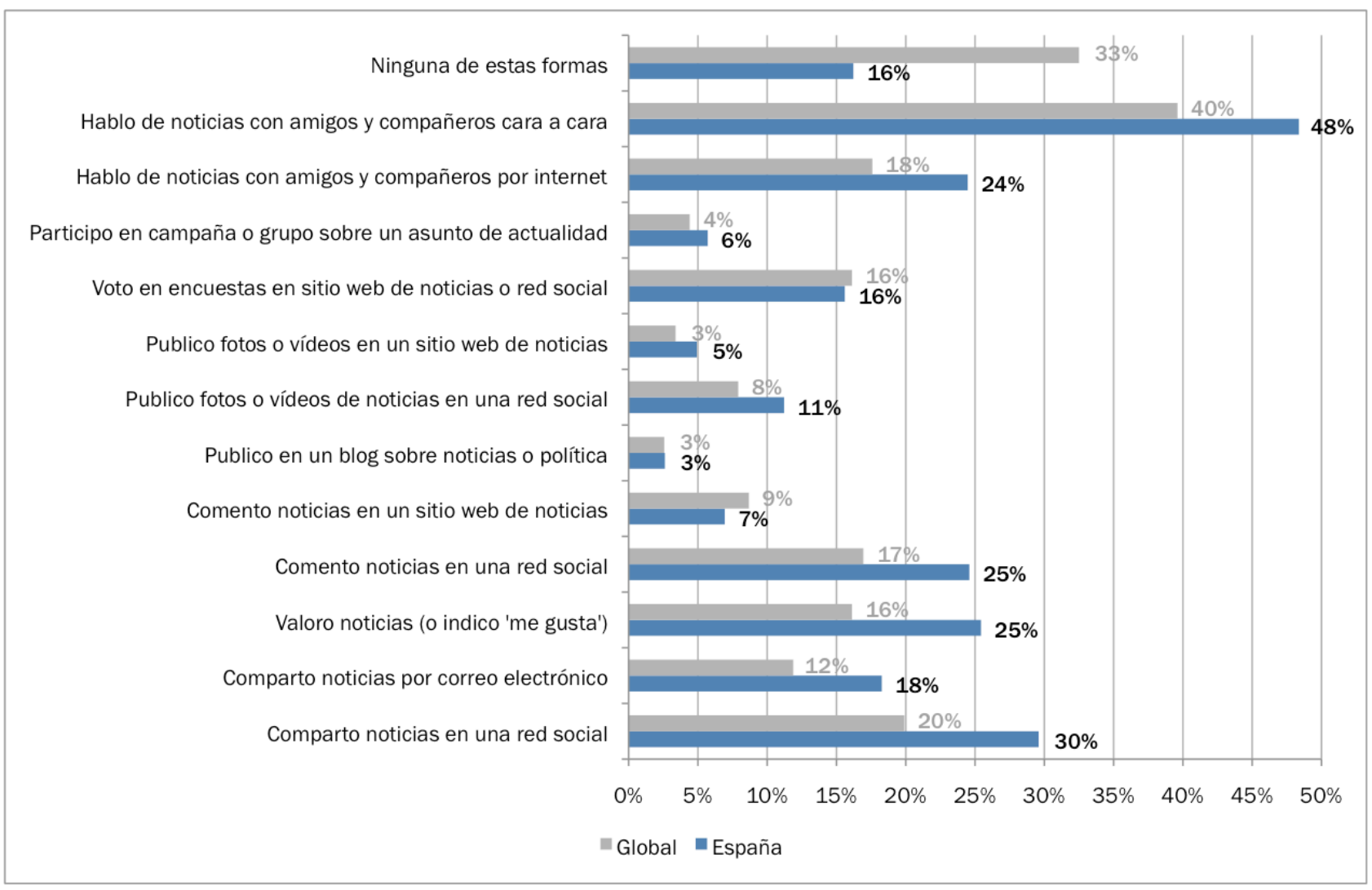


Las usuarias españolas están escasamente representadas en los comentarios adjuntos a las informaciones en los sitios web de noticias: participa de esta forma un $5 \%$ de mujeres, frente al 9\% de hombres. En el grupo de hombres de 25 a 34 años, los comentaristas en sitios de noticias llegan al 13\%, casi el doble de la media (entre las mujeres de esta franja de edad, apenas comenta en medios informativos digitales un 9\%); también son activos en los comentarios los hombres entre 18 y 24 años (12\%) y los que tienen entre 45 y 54 años (11\%).

Hay que destacar, además, que el porcentaje de usuarios que participan en los comentarios de los medios es muy similar en España, Reino Unido y Francia (7\%), y algo superior en Alemania (8\%), mientras que en Italia (13\%) y Estados Unidos (14\%) es prácticamente el doble.

Un 45\% de las mujeres usuarias entre 18 y 24 años comparte noticias en redes sociales, muy por encima del 30\% de media en España; un 31\% las puntúa o indica 'me gusta', y otro 31\% las comenta en redes sociales; en ambos casos, están 6 puntos porcentuales sobre la media.

Quienes más comparten noticias por e-mail son los usuarios y las usuarias de $\mathbf{4 5}$ años y más, un 23\%, frente al 10\% de usuarios adultos menores de 25 años que emplea este método.

Los hombres entre 25 y 34 años publican más fotos y vídeos de noticias en redes sociales que el resto de grupos: un 19\% frente al 11\% de media; las mujeres en esta franja de edad también destacan con un 13\%. Tanto mujeres como hombres en la franja de edad de 25 a 34 años, con un 8\%, y en la siguiente, de 35 a 44 años, con un 6\%, envían en mayor medida fotos y vídeos para su publicación en sitios web de medios informativos profesionales; el promedio es de apenas del $5 \%$.

Los comentarios cara a cara sobre la actualidad informativa son más frecuentes entre mujeres (53\%) que entre hombres (44\%), y también se dan más a menudo entre usuarios de noticias 'online' mayores de 35 años (50\%-52\%) que entre los menores de esta edad (42\%-44\%).

Las mujeres usuarias de noticias en internet entre 45 y 54 años también son las que más se movilizan para participar en campañas y grupos activos sobre asuntos de actualidad ( $8 \%$ ), dos puntos por encima de la media.

Durante el último año, ¿ha publicado algún comentario, pregunta, imagen u otros contenidos en una página web de noticias?

Posibilidad de respuesta múltiple (Base: 2.017 usuarios en España)

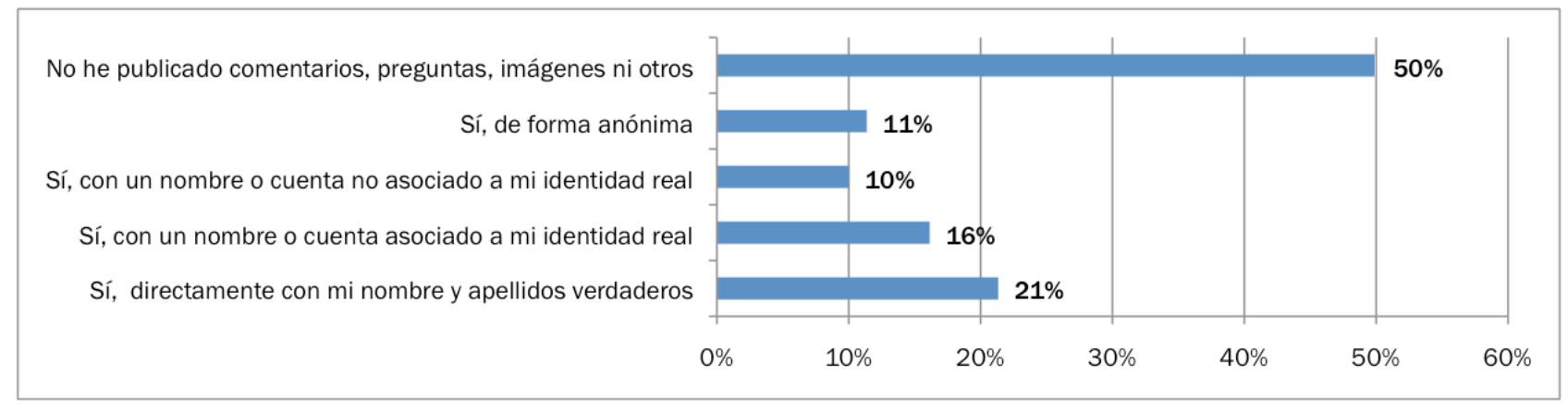

La mitad de la audiencia española participó en un sitio web de noticias en el último año, y la otra mitad, no. En la franja de edad de 25 a 34 años, participó un 75\% de hombres y un $48 \%$ de mujeres. Entre 18 y 24 años, publicó contenidos en sitios web informativos el $67 \%$ de hombres y el $43 \%$ de las mujeres encuestadas. Aunque el anonimato existe, redominan los casos en los que la contribución se puede asociar a la identidad del participante. 


\section{LOS USUARIOS PREFIEREN LOS MEDIOS PLURALES, NEUTRALES E IMPARCIALES}

- Cuatro de cada cinco personas valoran mejor el periodismo que refleja todas las opiniones, y que no defiende un solo punto de vista

- 7 de cada 8 confían más en los medios que se esfuerzan en ser neutrales e imparciales, frente a los abiertamente partidarios

- Los españoles conceden más importancia a la firma del periodista que a la marca de la publicación a la hora de otorgar credibilidad

La encuesta planteada a usuarios españoles incluía algunas preguntas sobre la fiabilidad que transmiten las diferentes fuentes de noticias y la medida en que se percibe una posible 0 potencial falta de objetividad en algunas de ellas o en sus periodistas.

El $\mathbf{8 1 \%}$ de los encuestados dice preferir "noticias en las que el reportero intenta reflejar una variedad de opiniones y deja en manos del lector o el espectador la decisión de decantarse por alguna de ellas", frente a un $\mathbf{1 9 \%}$ que se decanta por "noticias en las que el reportero defiende un punto de vista y proporciona pruebas a favor del mismo".

Piense en las diferentes fuentes de noticias a su disposición (como periódicos, emisoras o noticias en línea); ¿cuáles son las que le merecen mayor confianza (o credibilidad)?

Respuesta única. Las noticias provenientes de fuentes que... (Base: 2.017 usuarios en España)

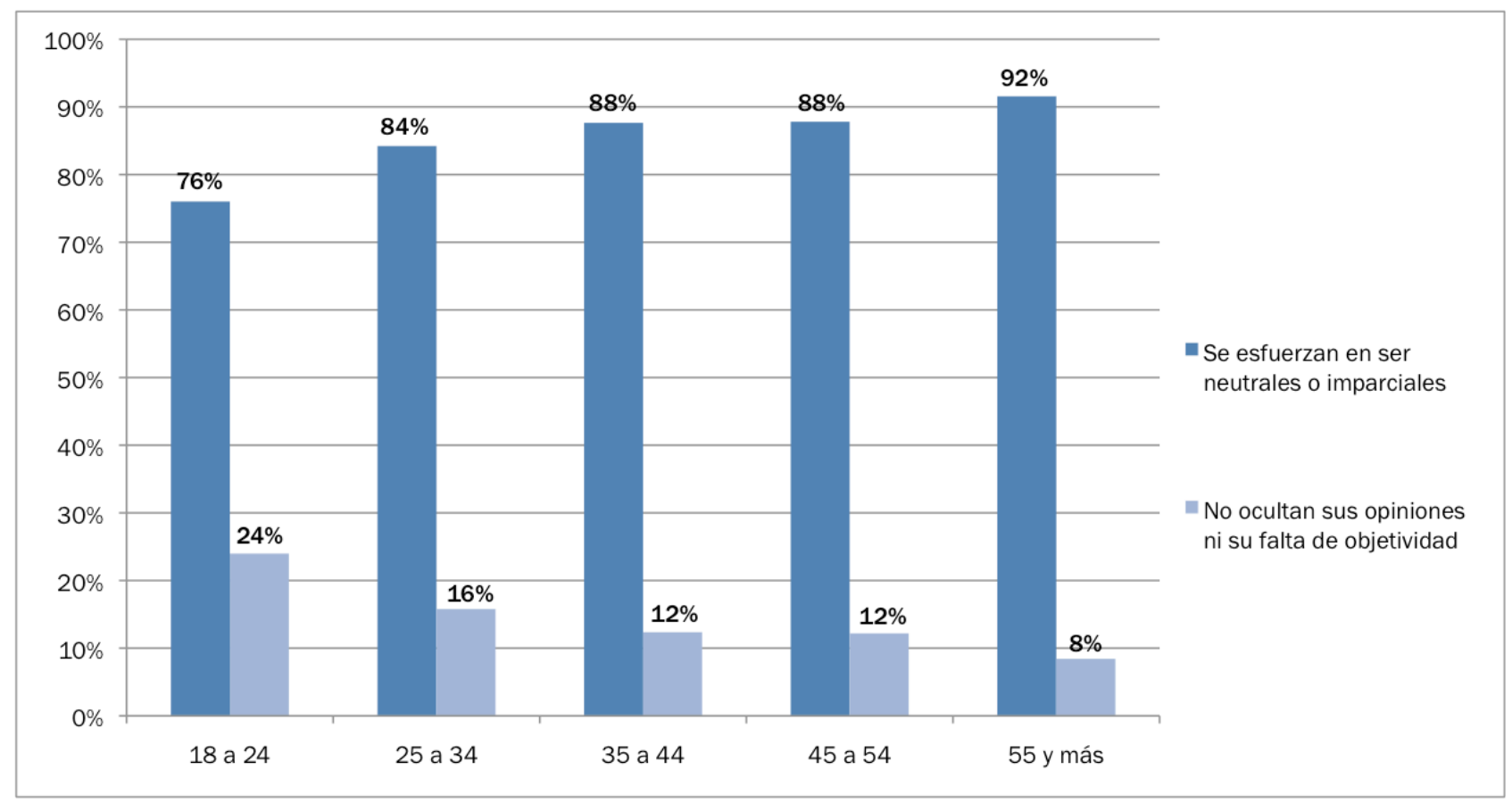


Una pregunta relacionada planteaba qué tipo de medio de comunicación merece más confianza o credibilidad. Los datos presentan diferencias más acusadas: a un $87 \%$ de usuarios le merecen más confianza o credibilidad los medios que se esfuerzan en ser neutrales o imparciales, frente a sólo un 13\% que otorga más confianza o credibilidad a los medios que no ocultan sus opiniones ni su falta de objetividad.

Se aprecia una evolución considerable en la respuesta sobre la credibilidad de los medios, según las distintas franjas de edad: entre los usuarios más jóvenes, que además se informan en mayor medida a través de las redes sociales, uno de cada cuatro confía más en los medios que son transparentes sobre su posición y no aspiran a trasladar una imagen de neutralidad.

\section{LA FIRMA DEL PERIODISTA ES UN POCO MÁS IMPORTANTE QUE LA CABECERA DEL MEDIO A LA HORA DE CONCEDER} CREDIBILIDAD A UNA NOTICIA, EXCEPTO ENTRE LOS JÓVENES

¿En qué medida le resultan importantes los siguientes elementos a la hora de otorgar su confianza a una fuente de noticias?

Elegir un calificativo de una escala para cada elemento: nombre o marca del medio, y periodistas concretos (Base: 2.017 usuarios en España)

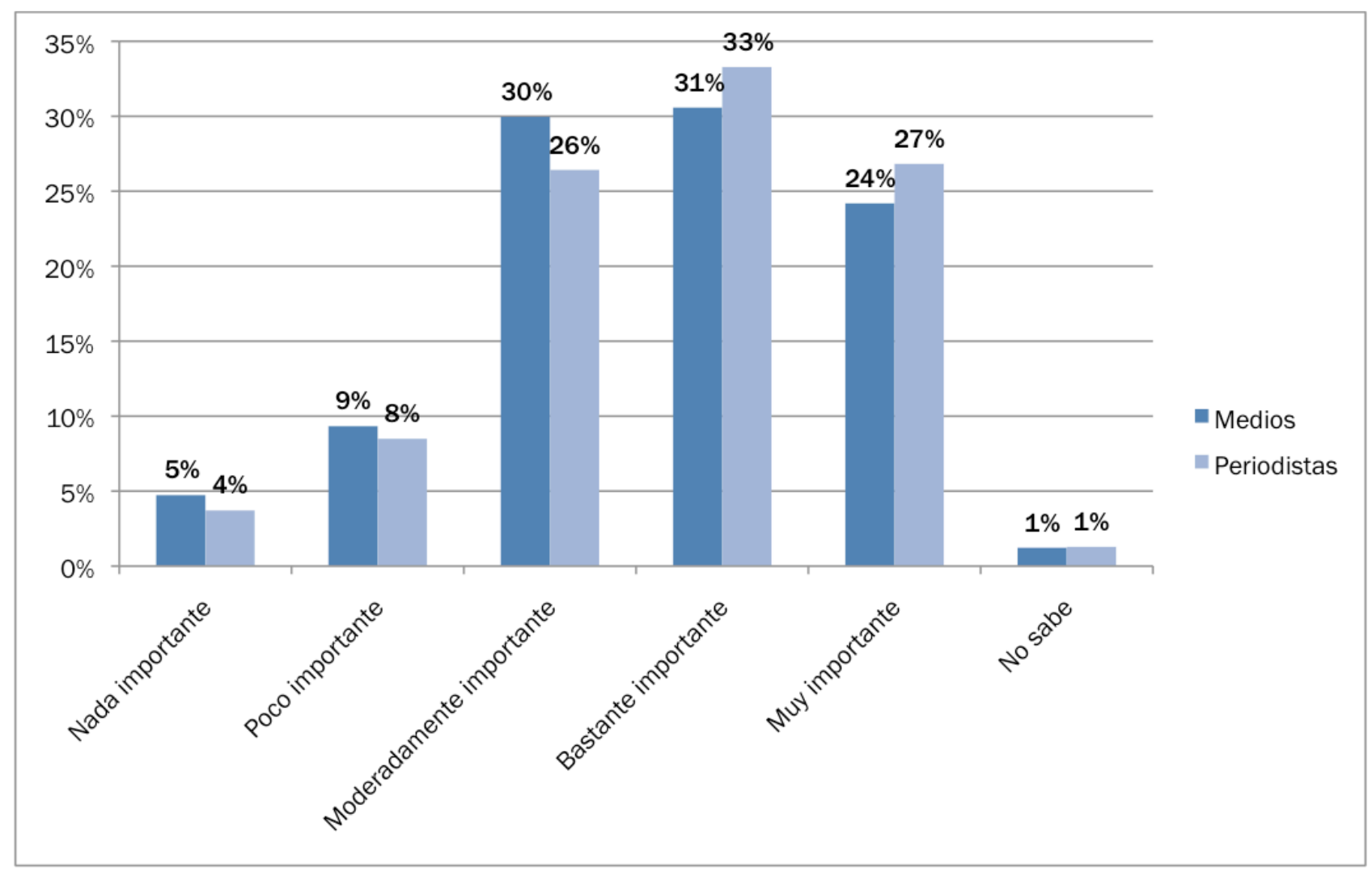

A la hora de decidir si confiar en una información, la marca o la cabecera del medio que la publica o difunde es "bastante" o "muy" importante para el $55 \%$ de los encuestados, y es "poco" o "nada" importante para apenas el 14\%, sin gran diferencia por sexo ni grupo de edad.

En general, un $60 \%$ de usuarios considera "bastante" o "muy" importante la firma del autor, en términos de confianza; son cinco puntos porcentuales más que los que estiman importante marca del medio. Un 12\% considera la firma poco o nada importante; dos puntos menos. 
Entre adultos menores de 25, se concede más importancia al medio (50\%) que al periodista (40\%). En la franja entre 25 y 34 años, el medio y el periodista, se valoran como "bastante" o "muy" decisivos por el $52 \%$ de los usuarios en ambos casos. La diferencia es muy baja en el grupo de entre 35 y 44 años: la firma (60\%) ya se sitúa dos puntos por encima de la cabecera. A partir de los 45 años de edad se abre la diferencia: la importancia de la firma del autor individual es 13 puntos porcentuales superior que la importancia otorgada a la marca. Los porcentajes son de $70 \%$ frente a 14\% hasta los 54 años, y $68 \%$ frente a $12 \%$ a partir de 55 .

\section{ESPAÑA ES EL ÚNICO PAÍS ENTRE LOS DIEZ SONDEADOS EN EL QUE IMPORTA MÁS LA CREDIBILIDAD DE LOS PERIODISTAS CONCRETOS QUE LA DE LAS MARCAS INFORMATIVAS}

Estos datos de confianza en periodistas y marcas entre usuarios de España son excepcionales entre todos los países en los que se realizó la encuesta: en ningún otro país otorgan los usuarios más credibilidad a los periodistas que a las cabeceras o marcas bajo las que muchos de ellos publican o difunden su trabajo.

En Alemania, la confianza en el medio aventaja en 29 puntos a la depositada en el periodista individual; en el Reino Unido, en 19 puntos; en Dinamarca, en 17 puntos; en Finlandia hay 16 puntos de diferencia en el mismo sentido; en Brasil, igualmente, el medio supera al periodista en 10 puntos; en Italia y Japón hay 6 puntos de ventaja; en EE. UU., el medio también se impone, allí por 4 puntos, y en Francia, por tres.

La importancia de la marca en España (55\%) se acerca más a la que tiene en Estados Unidos, Dinamarca y Finlandia (57\%), que a la que alcanza en Reino Unido y Francia (63\%) o Alemania (64\%). La importancia de la cabecera o marca del medio en Italia (72\%) es la más alta de Europa, pero los extremos se dan fuera del viejo continente: en Brasil, la marca del medio es importante para nada menos que el $82 \%$ de encuestados, y en Japón sólo para el 37\%.

La influencia de la firma del periodista concreto en la confianza que se otorga a las informaciones es similar entre los usuarios españoles y franceses (60\% en ambos países). Este aspecto es algo más importante para italianos (66\%) y japoneses (72\%), y algo menos para los usuarios de Estados Unidos (53\%), Reino Unido (44\%) y Dinamarca (40\%). La firma es importante sólo para un 35\% de usuarios alemanes y un 31\% de japoneses y finlandeses. 


\section{LAS MARCAS TELEVISIVAS GANAN ‘OFFLINE’, PERO LOS DIARIOS DOMINAN EN INTERNET}

\section{- Las cinco marcas informativas más mencionadas como favoritas en medios tradicionales pertenecen a Atresmedia, TVE y Mediaset}

- 'El País' lidera el papel y el conjunto de digitales. La SER, radio más fuerte en las ondas y 'online'. 'El Confidencial' gana en los sólo web

\section{- Las cabeceras locales, comarcales o autonómicas tienen un amplio seguimiento, pero en soporte impreso casi el doble que en internet}

La encuesta del Digital News Report 2014 en España también realizó el ejercicio de preguntar a los usuarios de internet que habían consultado noticias en el último mes cuáles eran las cabeceras o las marcas concretas de los tres medios tradicionales y los tres medios de internet en los que más habían seguido la actualidad informativa en la última semana.

¿Cuáles de los siguientes medios ha usado para acceder a las noticias durante la última semana? Posibilidad de especificar un máximo de tres (Base: 2.017 usuarios en España)

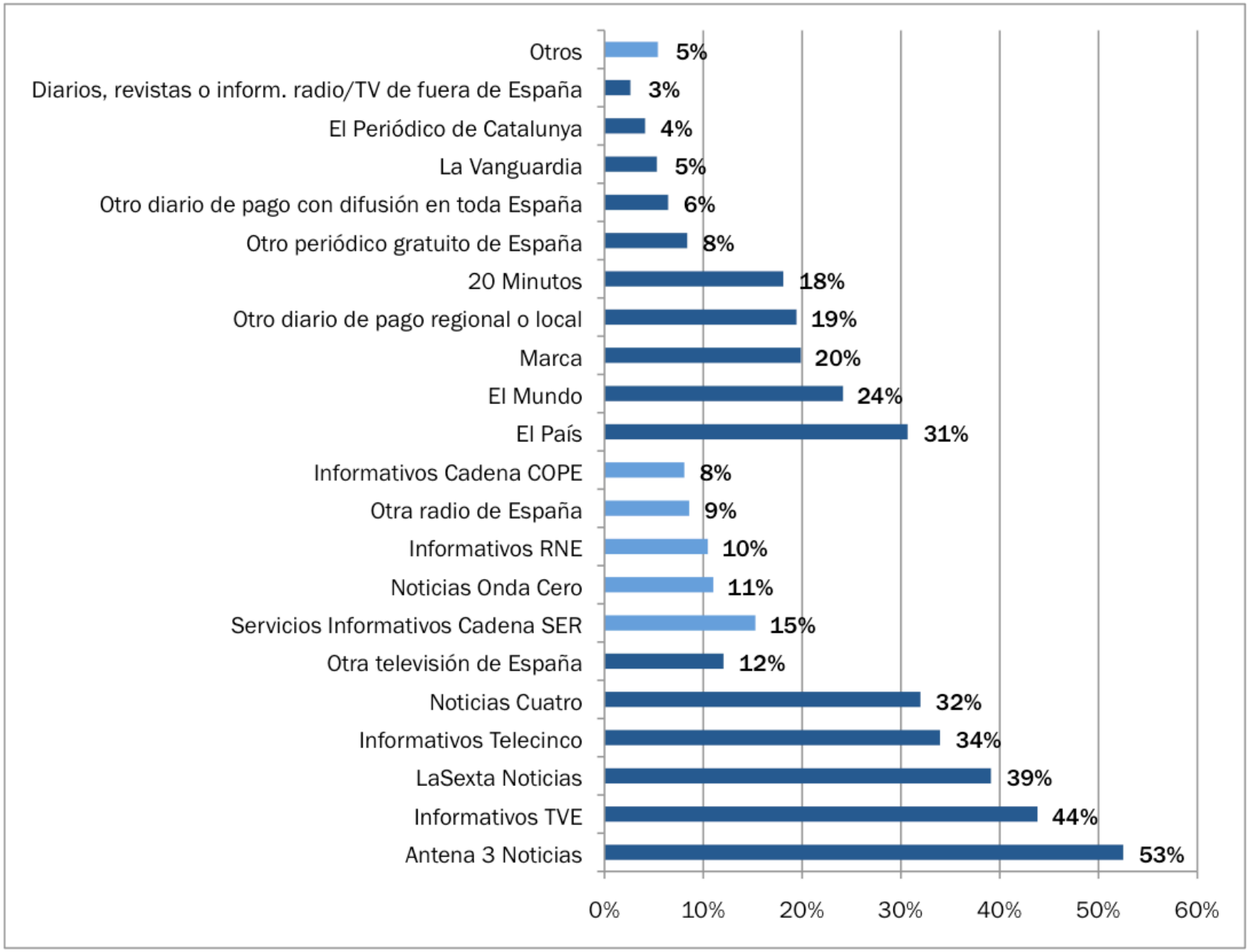




\section{ANTENA 3, TVE, LASEXTA, TELECINCO Y CUATRO SON LOS} MEDIOS MÁS SEGUIDOS FUERA DE INTERNET, SI SE PREGUNTA A LOS USUARIOS POR SUS TRES PREFERENCIAS INFORMATIVAS

Los cinco medios de referencia informativa son televisiones; por este orden, Antena 3, TVE, LaSexta, Telecinco y Cuatro. Si bien este ranquin no se corresponde tal cual con los índices, más precisos, que arroja la audimetría, hay que tener en cuenta para la encuesta la presencia más destacada de la actualidad informativa en unas y otras parrillas de televisión.

Los cinco medios siguientes por menciones de los usuarios, en los puestos del seis al diez, son periódicos: los de información general El País y El Mundo; el deportivo Marca; el conjunto de diarios de alcance autonómico, comarcal o local (excluidos El Periódico de Catalunya y La Vanguardia, que contaban con opción propia), y a continuación el gratuito 20 minutos.

Después, en los puestos del once al quince, vienen los informativos de las principales cadenas de radio: por este orden, SER, Onda Cero, el suma de las emisoras de Radio Nacional de España, el conjunto de otras emisoras (por ejemplo, las de ámbito autonómico), y COPE.

Obviamente, una encuesta en el conjunto del Estado, con una lista limitada de marcas propuestas, no puede replicar la complejidad del sistema de medios en mercados específicos. En el ámbito de la prensa, en la mayoría de Comunidades el índice de penetración más alto corresponde al diario regional líder, e incluso el segundo diario más leído, que se dirige al mismo público, se suele situar muy por encima de las cabeceras editadas fuera del territorio.

\section{EN CATALUÑA, LOS REFERENTES INFORMATIVOS EN PRENSA Y RADIO SON 'EL PERIÓDICO', 'LA VANGUARDIA' $Y$ LAS EMISORAS PROPIAS, PERO EN TV PREDOMINAN LOS CANALES ESTATALES}

Esta heterogeneidad se refleja especialmente en Cataluña. El 32\% de los encuestados indicó El Periódico de Catalunya entre sus tres preferencias informativas en el ámbito de medios tradicionales, y un $27 \%$ incluyó La Vanguardia en la terna, mientras que a El País le correspondió el 20\%, y el conjunto de los demás diarios de ámbito catalán alcanzó un 15\%, por delante de las demás opciones mayoritarias en el conjunto de España.

Además, entre los usuarios catalanes, para infomarse de las noticias, la opción 'otra radio' (sin contar las de fuera de España) alcanza un 11\%, más del doble que la siguiente clasificada, Informativos RNE (5\%). Las radios privadas de ámbito estatal SER, COPE y Onda Cero se quedan apenas entre el $4 \%$ y el $2 \%$. Las dos emisoras de radio generalista más escuchadas en Cataluña son la privada RAC1 (grupo Godó) y la pública Catalunya Ràdio, de acuerdo con las últimas oleadas del Estudio General de Medios (AIMC). 


\section{LOS SITIOS WEB DE PERIÓDICOS, REFERENTES PARA}

\section{LOS USUARIOS DE ESPAÑA, SEGUIDOS POR LA VERSIÓN DIGITAL DE LOS INFORMATIVOS DE TELEVISIÓN}

¿Cuáles de los siguientes medios ha usado para acceder a las noticias durante la última semana? Posibilidad de especificar un máximo de tres (Base: 2.017 usuarios en España)

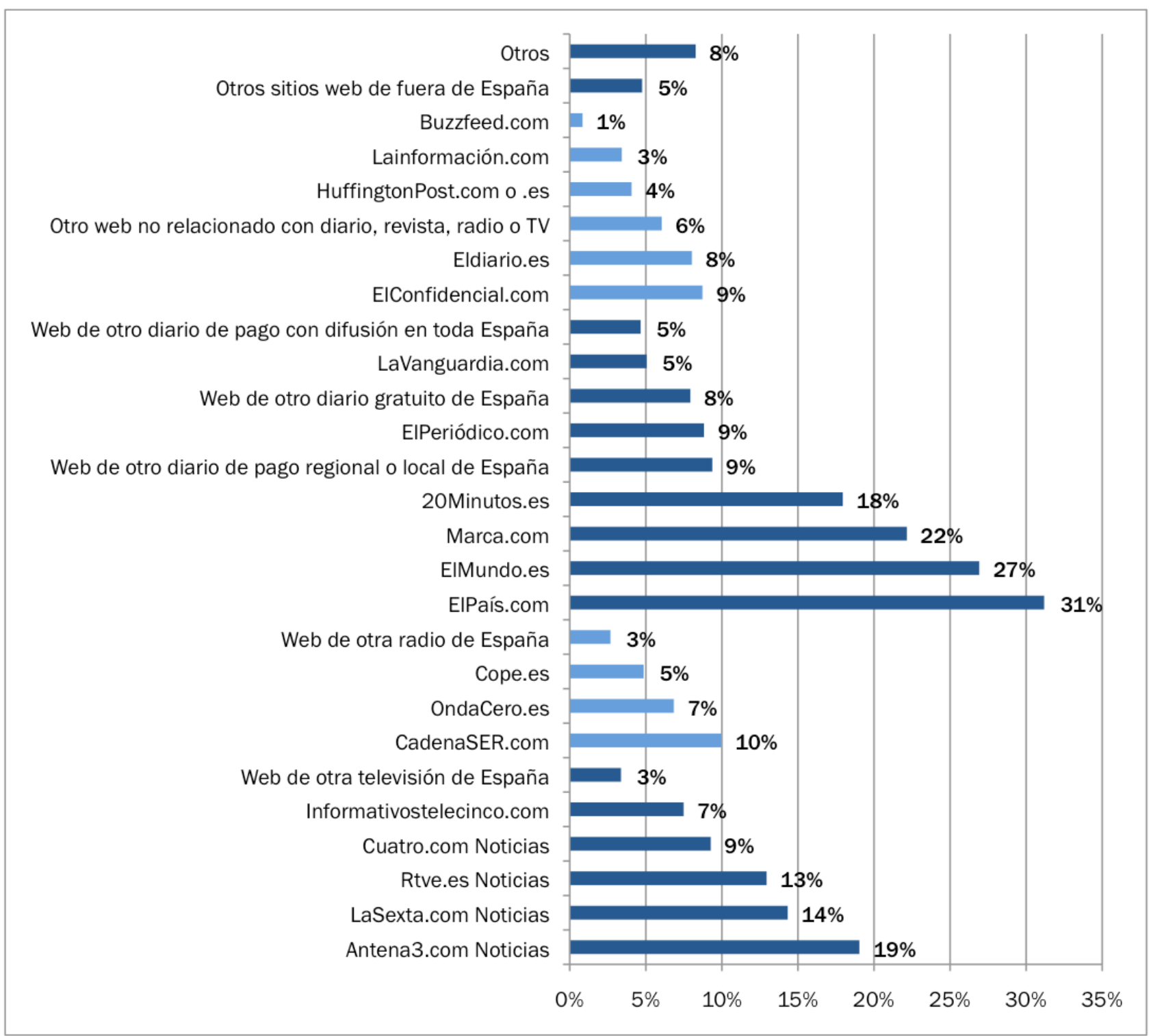

Los medios digitales de noticias más consultados por las personas que respondieron en la encuesta son los sitios web de El País (31\%), El Mundo (27\%), el deportivo Marca (22\%), Antena 3 Noticias (19\%), y cierra los cinco puestos de cabeza el sitio de 20 Minutos (18\%).

Por tanto, los sitios web de diarios se confirman como referencia informativa, si bien el principal portal informativo de televisión del grupo Atresmedia se cuela en la cuarta posición, y el sexto lugar es, precisamente, para la presencia web de LaSexta Noticias, la otra oferta televisiva del mismo grupo. Seguidamente, en séptimo lugar, se situaría el portal de noticias de RTVE.es (13\%). 
En octava posición se encuentra el primer cibermedio asociado a una emisora de radio: CadenaSER.com, que es señalado por el 10\% de los encuestados. Cerrando los diez puestos de cabeza, Noticias Cuatro, del grupo Mediaset, y ElConfidencial.com, primer medio sólo digital de esta lista, ambos con 9\% de menciones.

\section{ELCONFIDENCIAL.COM Y ELDIARIO.ES, DOS MEDIOS EXCLUSIVAMENTE DIGITALES DE ÉXITO CON PERFILES DE AUDIENCIA MUY DISTINTOS SEGÚN EDADES}

Por edades, destaca el perfil de Eldiario.es, siguiente medio exclusivamente 'online' en la clasiificación, que marca un 16\% de menciones en el grupo de 18 a 24 años, lo que lo coloca en el $7^{\circ}$ lugar de preferencias entre los adultos más jóvenes, por detrás de Elpaís.com (33\%), Marca.com (31\%), 20minutos.es (29\%), Elmundo.es (26\%), y las noticias de Antena3.com (23\%) y laSexta.com (17\%). El medio dirigido por Ignacio Escolar marca un 10\%, 8\%, 7\% y 5\% de menciones en los siguientes franjas, de menor a mayor edad.

EIConfidencial.com alcanza un máximo del 12\% de menciones en el grupo de usuarios a partir de 55 años, mientras que en las franjas de 25 a 54 años oscila entre el $7 \%$ y el 9\%, y sólo lo menciona el $4 \%$ de los adultos menores de 25 años.

Generalmente, la evolución por edades es más estable en el caso de los sitios web de los diarios generalistas de pago y los de los informativos de las radios y las televisiones.

Sin embargo, quienes citan el sitio web de información deportiva Marca.com entre sus preferencias alcanzan un máximo del 31\% entre 18 y 34 años (segunda opción más popular en estas franjas tras Elpaís.com); bajan al 24\% y al 18\% en las franjas de 35 a 44 y de 45 a 54 años, respectivamente, y se quedan en el 15\% entre los usuarios de 55 años y más.

Otro de los medios con diferencias acusadas por edades es 20minutos.es, quinto en el ranquin general: resulta muy popular entre los lectores de 18 a 34 años, franjas en las que es mencionado por el $29 \%$ de los usuarios, lo que lo convierte en el tercer medio más popular entre los adultos menores de 25, tras Elpaís.com y Marca.com; de 35 a 54 años, lo eligen entre sus tres favoritos un 16 o 17\% de los encuestados, mientras que a partir de los 55 años lo nombra sólo el 8\%. 


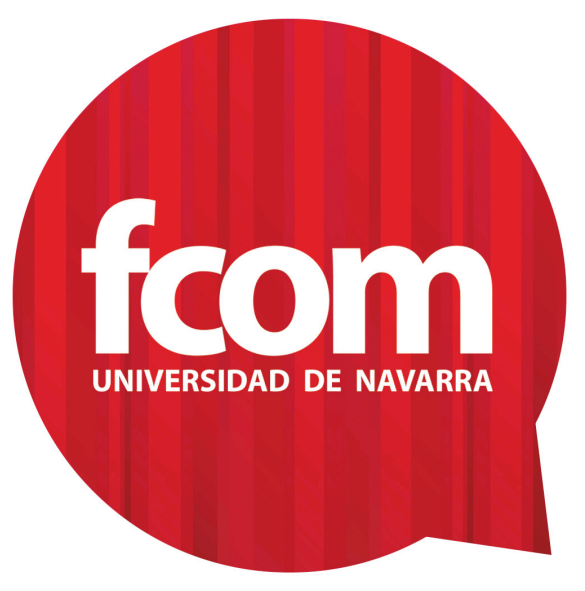

unav.edu/web/digital-studies

\#DigitalNewsES @digitalunav 